WIDER Working Paper 2021/189

Dynamic impacts of lockdown on domestic violence

Evidence from multiple policy shifts in Chile

Sonia Bhalotra, ${ }^{1}$ Emilia Brito, ${ }^{2}$ Damian Clarke, ${ }^{3}$ Pilar Larroulet, ${ }^{4}$ and Francisco J. Pino ${ }^{5}$

December 2021 
Abstract: We leverage staggered implementation of lockdown across Chile's 346 municipalities, identifying dynamic impacts on domestic violence. Using administrative data, we find lockdown imposition increases indicators of distress related to domestic violence, while decreasing domestic violence reports to the police. We identify male job loss as a mechanism driving distress, and female job loss as driving decreased reporting. Stimulus payments to poor households act on both margins, their impacts partially differentiated by lockdown status. Once lockdown is lifted, police reports surge but we see a ratchet effect in distress. Our findings accentuate the controversy around welfare impacts of lockdown mandates.

Key words: domestic violence, social safety net, public health, COVID-19

JEL classification: J12, I38, H53

Acknowledgements: We are grateful for funding and feedback to the NBER Research Grants on Women, Victimization, and COVID-19 (Bill \& Melinda Gates Grant), The Ministry of Science Chile (ANID grant COVID00593), the Centre for Social Conflict and Cohesion Studies (ANID/FONDAP/15130009), and UNU-WIDER. Bhalotra acknowledges partial funding for her time from ESRC grant ES/M010263/1 for the Human Rights Big Data and Technology Project (hrbdt.ac.uk) at the Human Rights Centre, University of Essex, and Clarke acknowledges partial funding from the Millennium Institute on Market Imperfections and Public Policy. This research has been approved by the IRB at PUC Chile (200720006) and FEN Universidad de Chile (\#02/2021). We are grateful to Fernanda Bosco, María José Diaz, María José Abud, and Javiera Ruiz-Tagle from Chile's Ministry for Women and Gender Equality for support with data and many useful discussions, and to Pinar Keskin and participants at the NBER conference for multiple useful suggestions. We thank Daniel Pailañir for outstanding research assistance.

Note: tables and figures at the end of the paper, before the appendix

\footnotetext{
${ }^{1}$ University of Warwick, CEPR, IEA, CAGE, and IZA; 2 Brown University, Department of Economics; ${ }^{3}$ University of Chile, Department of Economics, MIPP and IZA, corresponding author: damian.clarke@uchile.cl; 4 Pontificia Universidad Católica de Chile, Instituto de Sociología; ${ }^{5}$ University of Chile, Department of Economics and IZA

This study is published within the UNU-WIDER project Women's work - routes to economic and social empowerment.

Copyright (C) UNU-WIDER 2021

UNU-WIDER employs a fair use policy for reasonable reproduction of UNU-WIDER copyrighted content-such as the reproduction of a table or a figure, and/or text not exceeding 400 words-with due acknowledgement of the original source, without requiring explicit permission from the copyright holder.
}

Information and requests: publications@wider.unu.edu

ISSN 1798-7237 ISBN 978-92-9267-129-7

https://doi.org/10.35188/UNU-WIDER/2021/129-7

Typescript prepared by Siméon Rapin.

United Nations University World Institute for Development Economics Research provides economic analysis and policy advice with the aim of promoting sustainable and equitable development. The Institute began operations in 1985 in Helsinki, Finland, as the first research and training centre of the United Nations University. Today it is a unique blend of think tank, research institute, and UN agency — providing a range of services from policy advice to governments as well as freely available original research.

The Institute is funded through income from an endowment fund with additional contributions to its work programme from Finland, Sweden, and the United Kingdom as well as earmarked contributions for specific projects from a variety of donors.

Katajanokanlaituri 6 B, 00160 Helsinki, Finland

The views expressed in this paper are those of the author(s), and do not necessarily reflect the views of the Institute or the United Nations University, nor the programme/project donors. 
Since the start of the COVID-19 pandemic, reports of a substantial surge in domestic violence have emerged from several countries, a phenomenon referred to as the shadow pandemic (UN Women 2020). The fact of an almost universal increase suggests common mechanisms at play. In this paper we investigate the role of lockdown mandates. Analysis of optimal lockdown policy has focused on the trade off between fatalities and economic growth (Alvarez et al. 2021). We extend the scope of debate over lockdown mandates by investigating their impact on domestic violence (DV). We also provide estimates of the extent to which income support schemes have mitigated impacts on DV, allowing differences in impacts by lockdown status.

We investigate two mechanisms by which lockdown can lead to DV, which are job loss and mobility restrictions. Lockdown is associated with a decline in economic activity, manifest in employment and earnings losses. Recent evidence suggests that individual job loss triggers DV by generating both a negative income shock (that generates stress) and a positive time shock (that increases exposure or opportunities for crime) (Bhalotra et al. 2021). The mobility restrictions imposed by lockdown reinforce exposure. Additionally, by forcing isolation from social networks, they may impact the mental health of men and women, and limit the freedom of the victim to seek social or state support. ${ }^{1}$

Numerous studies have analysed the phenomenal increase in DV since the pandemic. ${ }^{2}$ Our contribution lies in providing the first unbiased estimates of dynamic impacts of both entry to lockdown and exit from lockdown on multiple indicators of domestic violence, and in investigating the relevant mechanisms.

The study is set in Chile, which has implemented rolling lockdowns at municipality level. We analyse the first wave of COVID-19 when, between March and September 2020, lockdown was imposed in 116 of Chile's 346 municipalities, generating 116 natural experiments, which we stack in an event-study design. Events of lifting lockdown provide a further series of experiments. We investigate both imposition and lifting of lockdown, estimating dynamic impacts while allowing for treatment effect heterogeneity using the de Chaisemartin and D'Haultfœuille (2020) estimator. The identifying assumption is that the timing of lockdown mandates is conditionally random. We scrutinize this by displaying placebo or anticipation effects, with and without conditioning upon COVID-19 infection and test rates. To allow for the possibility that we are underpowered to detect differences in pre-trends, we additionally study the sensitivity of our estimates to violations of the assumption of counterfactual parallel trends, following Rambachan and Roth (2021).

We use high-frequency administrative data on three alternative measures of DV that, together, capture incidence, tolerance, and reporting, allowing that lockdown mandates may have acted differently on these margins. ${ }^{3}$ We gather administrative data on the exact dates at which municipalities enter and exit lockdown, tri-weekly indicators of COVID-19 infection and testing rates, daily data on mobility

\footnotetext{
${ }^{1}$ A number of studies indicate a deterioration of mental health during the pandemic; for instance, Giuntella et al. (2021), Etheridge and Spantig (2020). The latter show that women suffer more, and that isolation from social networks plays a role in this.

2 Without attempting to be comprehensive, we refer to Leslie and Wilson (2020), Sanga and McCrary (2020), Hsu and Henke (2021), Bullinger et al. (2020), Miller et al. (2020), Agüero (2021), Perez-Vincent et al. (2020), Anderberg et al. (2020), Berniell and Facchini (2021), Piquero et al. (2020), Ravindran and Shah (2020), Silverio-Murillo et al. (2020), Asik and Nas Ozen (2021), Arenas-Arroyo et al. (2021) and Beland et al. (2020), Gibbons et al. (2020), Chalfin et al. (2021), Ivandić et al. (2020), Erten et al. (2021).
}

${ }^{3}$ We restrict attention to cases where men are perpetrators and women are victims. 
from cell phone towers, monthly data on formal sector employment rates, and monthly data on stimulus payments.

We find that imposition of lockdown in a municipality is associated with an increase in calls to a policemanaged DV helpline (\#149 - Fono Familia) and increased occupancy of public shelters for abused women, alongside a decrease in formal crime reports to the police. This suggests an increase in distress that coincides with more limited redress. The placebo effects are consistent with the timing of lockdown mandates being idiosyncratic. In general, the dynamic effects of lockdown intensify with lockdown duration, and lockdown mandates act to reinforce impacts of COVID-19 on helpline calls (distress) and crime reports (redress seeking). ${ }^{4}$

Lifting lockdown generates a reversal in these patterns, but to varying degrees. We identify a ratchet effect in calls to the police, with calls remaining significantly higher than they were before lockdown was initiated, consistent with in-built persistence in DV within couples. There is no similar persistence in shelter use or in DV crime reports. The decline in crime reports is completely reversed, consistent with pent-up demand, and reported cases after exit from lockdown are higher than they were before initiation of lockdown, mirroring the behaviour of distress calls. ${ }^{5}$

Impacts of both lockdown entry and exit on mobility and unemployment line up with the estimates for DV outcomes, consistent with these being relevant mechanisms. Lockdown imposition results in sharp declines in mobility and employment. Both exhibit some persistence after lockdown is lifted, potentially explaining the ratchet effect in helpline calls. In contrast to emerging results for other OECD countries (Adams-Prassl et al. 2020; Cajner et al. 2020; Farré et al. 2020), we find that lockdown had a larger impact on male than on female job loss in Chile. ${ }^{6}$ Using a shift-share approach, we show that male job loss contributes to explaining impacts of lockdown on incidence, and that female job loss contributes to explaining decreased reporting.

Further insight into the mechanisms leading from lockdown to domestic violence is gained by analysing impacts of federal stimulus payments targeted at low-income households. After establishing that we use idiosyncratic municipality-month variation in payouts under this scheme, we find that it was associated with lower DV incidence and higher reporting in general, and that the moderating impact on incidence (measured by helpline calls) was larger in municipalities that were in lockdown.

Overall, the results are consistent with income shocks and exposure being mechanisms driving perpetration by men, and with reporting being sensitive to the woman's financial position. Many existing studies and recent media coverage discuss impacts of lockdown on exposure, but do not consider the role of job loss or identify causal impacts of income support.

Recent research establishes a case for lockdown, showing that voluntary social distancing is below the socially optimal level (Eichenbaum et al. 2021; Farboodi et al. 2021; and Toxvaerd 2020). It is estimated that the optimal policy involves losing 6 per cent of one year's GDP (or, equivalently, a permanent

\footnotetext{
${ }^{4}$ Shelter occupancy is an exception to this pattern insofar as infection rates lead to lower rates of shelter use, which is consistent with the risk of infection acting as a deterrent. Conditional upon infection rates, lockdown increases shelter use just as it increases helpline calls, marking an increase in DV incidence or distress.

${ }^{5}$ Effect sizes computed as weighted averages of the dynamic coefficients indicate that lockdown entry leads to an escalation of calls by 106 per cent, and lockdown exit only partially reverses this, such that calls remain 50 per cent higher than they were before lockdown. Lockdown entry increases shelter use by 10 per cent, and lockdown exit more than reverses this, with shelter use falling to about 7 per cent below its baseline level. Crime reports decline by 4.5 per cent after lockdown is imposed, and then they shoot up by 10.1 per cent, thus remaining about 5.6 per cent above their baseline level.

${ }^{6}$ Lockdown imposition reduces mobility by 35 per cent. After lockdown is removed, mobility only partially recovers, remaining 13 per cent below baseline. Lockdown imposition reduces male employment by 3.4 per cent. Lifting lockdown again generates only partial recovery, with employment remaining 1.5 per cent below its baseline level.
} 
reduction of 0.3 per cent), and that the total welfare costs are more than four times bigger due to the cost of deaths (Alvarez et al. 2021). Our estimates suggest that current models underestimate the welfare costs of lockdown.

Section 2 details the estimation strategy. The DV outcomes are analysed in Section 3, and the mechanisms in Section 4. Policy remediation is analysed in Section 5, and Section 6 concludes.

\section{Empirical design}

\subsection{Rolling lockdown entry and exit}

We analyse the first COVID-19 wave in Chile, 14 March to 30 September 2020, during which 116 of the 346 municipalities entered lockdown, with entry and exit graduated across municipalities over time. On 30 September, 73 municipalities had exited lockdown. Essential workers including hospital and supermarket workers were exempt, but otherwise the mandate was strict, with citizens allowed to go out just twice a week for three hours at a time, using a permit. Violations of lockdown conditions could be penalized with fines of up to 10 million Chilean pesos (US\$12,000) or short prison terms. Police personnel conducted spot checks, and thousands of individuals were penalized.

Lockdown was put in place at the discretion of the Ministry of Health based upon their assessment of the spread of the virus and the risk of contagion, but there was no declared metric, as a result of which announcement of the mandate at the municipality level was unexpected. Once announced, lockdown took effect within 1-3 days and lasted between 6-172 days, with an average length of 32.5 days. When lockdown was lifted, it was initially lifted for weekdays and only subsequently for weekends as well.

We compiled data on COVID-19 infection and testing rates from open repositories updated several times a week by the Chilean Ministry of Science. We manually gathered data on the exact dates of entry to and exit from lockdown for each municipality, available for other researchers here. ${ }^{7}$ Figure 1 provides a snapshot of the dynamics of entry and exit for the country. We created a video describing the dynamic nature of lockdown entry and exit, available here. ${ }^{8}$

\subsection{Empirical specification}

We look to identify impacts of lockdown imposition and lockdown removal on the three indicators of domestic violence, mobility, and male and female employment. Identification leverages temporal variation in exposure to lockdown across municipalities. Denote domestic violence $D V_{s, t}$, where $s$ indexes municipalities and $t$ indexes time. Motivated by the descriptive trends presented in Figures A1 and A2, we use the de Chaisemartin and D'Haultfœuille (2020) estimator $\left(D I D_{M}\right)$ to obtain unbiased estimates of dynamic and placebo effects. Denote lockdown status $Q_{s, t}$, which takes the value of 1 if lockdown is in place in municipality $s$ at time $t$, and 0 if not. Then define:

$$
D I D_{+, t}^{\text {Lockdown }}=\sum_{s: Q_{s, t}=1, Q_{s, t-1}=0} \frac{N_{s, t}}{N_{(1,0), t}}\left(D V_{s, t}-D V_{s, t-1}\right)-\sum_{s: Q_{s, t}=Q_{s, t-1}=0} \frac{N_{s, t}}{N_{(0,0), t}}\left(D V_{s, t}-D V_{s, t-1}\right),
$$

which for a particular $t$ is the change in mean outcomes between $t-1$ and $t$ among municipalities which adopted lockdown (switchers), relative to those that did not (non-switchers). The estimates are consistently weighted by municipality population, $N_{s, t}$, though we confirm that the broad results are not

\footnotetext{
${ }^{7}$ Full URL: https://github.com/Daniel-Pailanir/Cuarentenas

${ }^{8}$ Full URL: https://bit.ly/3pUeULZ
} 
sensitive to weighting. We create an estimate of the average impact of lockdown imposition by taking the weighted average over all time-periods in which any switch occurs, the weight being the share of individuals switching in the equation at each $t$ :

$$
D I D_{M}^{\text {Lockdown }}=\sum_{t=2}^{T} \frac{N_{(1,0), t}}{N} D I D_{+, t}^{\text {Lockdown }}
$$

In estimating dynamic effects, rather than compare levels at $t$ with those at $t-1, D I D_{M}$ compares levels in subsequent periods $t+k \forall k \in\{1, \ldots, K\}$ to those at $t-1$. Similarly, placebo (pre-lockdown) coefficients are estimated by comparing periods entirely unaffected by the lockdown, specifically comparing average changes in time periods $t-2, t-3, \ldots, t-L$ with levels in period $t-1$. We conduct inference on each parameter using a block (cluster)-bootstrap based on municipalities and consistently include as many post-treatment lags as are available in the data.

In order to capture only impacts of lockdown imposition, and not any additional impacts once municipalities exit lockdown, the analysis sample includes municipalities up until the point that they graduate out of lockdown. Estimates of impacts of lockdown exit are obtained analogously to estimates of entry. In the lockdown exit plots, pre-event coefficients compare municipalities that are all in lockdown, treated municipalities being those that in the future exit lockdown and control municipalities being those that remain in lockdown. The coefficient at time zero compares municipalities which exited lockdown between the current and previous period to those that remained under lockdown. By definition, the $D I D_{M}$ estimator captures municipality and month (or, in the case of shelter use, day and region) fixed effects (FE). All schools closed nationwide on 16 March, and thus impacts of school closure are absorbed by time FE. We control for COVID-19 infection, testing, and positivity rates and also show results without these controls. Other predictors of lockdown timing such as population density are absorbed by municipality FE.

The $D I D_{M}$ estimator resolves potential bias arising in two-way FE model estimates when treatment varies over time and there is heterogeneity in treatment effects across units and time. It is not sensitive to compositional changes that arise as different municipalities enter (or exit) treatment. The identifying assumption is that the exact timing of lockdown mandates is quasi-random conditional upon municipality and year FEs. The placebo (pre-event) coefficients provide a partial test of parallel trends, as they reveal whether switchers and non-switchers had similar outcome trends at least prior to the imposition of lockdown. ${ }^{9}$

Although we will see that the placebo effects support the identifying assumption, we study sensitivity of our estimates to violation of parallel trends, following Rambachan and Roth (2021) to estimate partially identified 'Honest DiD' bounds, derived under the assumption that pre-lockdown trends are projected forward. These tests are useful, as they let us consider not only strict projection of any pre-treatment trends, but also bound post-treatment estimates in cases where these trends may further diverge from linearity. As such, for each lag we present bounds under a range of settings, projecting pre-trends and allowing up to another 0.1 per 100,000 unit divergence between each period. As the bounds are applied to the standard DiD estimator, we obtain the diagnostics for bias in the standard estimator (de Chaisemartin and D'Haultfœuille 2020; Goodman-Bacon 2021). These show between zero and 2.1 per cent negative weights (Table A1), suggesting small, if any, bias in the standard estimator. This is consistent with our sample containing a large share of never-treated municipalities.

\footnotetext{
9 The de Chaisemartin and D'Haultfœuille (2020) pre-trend coefficients differ from the standard test of pre-trends in event studies (Autor 2003), which are potentially invalid when treatment effects are heterogeneous (Sun and Abraham 2021).
} 
All variables used in the analysis are described in the Data Appendix (Appendix B) along with descriptive plots. Most outcomes are measured at the municipality-month level, but shelter use is at the region-day level. The descriptive plots reveal that the outbreak of the pandemic was associated with sharp increases in calls to the DV helpline and in use of public shelters, and a decrease in reported DV crimes. In this section, we provide estimates of causal effects of lockdown entry and exit conditional on the pandemic outbreak, and the fact that lockdown was imposed and lifted at different dates across municipalities. The results for DV indicators are in Figure 2, and for mobility and male and female employment rates in Figure 3.

Our main results are as follows. Lockdown imposition leads to an increase in DV helpline calls and public shelter use, but a decrease in DV crime reports. Investigating lifting of lockdown, we identify ratchet effects in distress calls (and in unemployment, a mechanism), alongside displacement effects in formal police reports. We demonstrate that job loss is a mechanism, with male and female job loss triggering changes in incidence and reporting, respectively, and we show that income support mitigates impacts of lockdown.

\subsection{Distress calls to the DV hotline}

We obtained records of all calls to the DV hotline of the Chilean Police at the month $\times$ municipality level. Calls capture fairly serious concerns. The number is formally linked to the police and calls are geographically tracked. In cases where the call relates to an emergency, a patrol car is sent to the victim's address, and this results in a formal crime report. However, not all calls result in criminal complaints and, conversely, criminal complaints can be initiated without first calling this hotline. Panel (a) of Figure 2 indicates an increase in DV helpline calls following lockdown imposition that increases sharply three months in. It shows parallel pre-trends for lead months -18 up until -2 . There is a small but noteworthy increase in the month preceding lockdown consistent with our observation that coronavirus infections show a rise, on average, five weeks before lockdown, leading to voluntary distancing and stress. Averaging the dynamic effects over the first three (six) months following lockdown gives a 88 per cent (106 per cent) increase. ${ }^{10}$

Panel (b) shows that DV calls fall with lockdown removal, the decline increasing over time. The averaged coefficients show that only 50 per cent of the increase in calls following lockdown imposition is reversed, indicating a ratchet effect. This is consistent with wider evidence of path dependence in DV. Helpline calls are tagged as being related to physical, psychological, or economic violence. Analysing them separately, we find that lockdown drives roughly similar proportional increases in all three. However, as economic violence is an order of magnitude less frequent than other types, the coefficients for it border on significance (Appendix Table A3).

\subsection{Occupancy of public shelters for abused women}

We have day $\times$ region data on occupancy rates the night before day $t$. Panels (c)-(d) of Figure 2 show that the placebo coefficients closely track the zero line until the event of lockdown imposition or removal. After imposition, there is a sharp and increasing rise in public shelter use that persists through the 80-day window, although the coefficients become imprecise after about the 15-day mark, reflecting that the data

10 The spike after three months is based on a smaller number of municipalities, see Table A2. 
grow more scarce as we move forward from the event date. The average indicates a 10 per cent increase. This is reversed once lockdown is lifted. ${ }^{11}$

Shelter occupancy will underestimate the demand for shelter during the pandemic if women perceive shelter use as elevating the risk of infection. Although Chilean shelters had infection-limiting protocols, we see evidence consistent with this in Table A4, which shows that a higher COVID-19 infection rate (which is included as a control in the analysis) is associated with lower shelter use, even though it is associated with more helpline calls. We retain shelter use as it is a 'harder' indicator of DV than distress calls, possibly capturing more extreme cases. It is still useful to study helpline calls, as these are not directly sensitive to infection concerns and will capture cases of varying intensity.

Given the sharp surge in DV following outbreak of the pandemic, we investigated whether the occupancy rate might underestimate shelter demand for a different reason, which is that shelters were filled to capacity. This does not appear to be the case. First, before the pandemic struck, there were spare spaces in shelters, the average occupancy rate was 62 per cent, with a standard deviation of 42 per cent. Second, using the $\mathrm{DID}_{M}$ estimator, we estimated impacts of lockdown on shelter capacity and found an (imprecise) increase of 1.3 per cent in shelter spaces (Figure A3).

\subsection{Police reports of DV}

We obtained month $\times$ municipality-level data on DV crimes filed with the police. Panels (e)-(f) of Figure 2 show that lockdown results in a significant decline of 4.5 per cent in reporting DV. As this is despite the increase in distress calls and shelter use that we observe, it indicates impediments to reporting. Lockdown may create one or more of these impediments: female job loss, which leaves women economically vulnerable and more likely to tolerate DV; isolation from social networks which may make it harder to report for women who need support taking the decision to report; mobility restrictions make it harder to go into police or prosecutor offices to report; in the first wave, police capacity may have been compromised by social distancing rules and officer absences; or proximity to the perpetrator may make it harder to report and/or intensify the fear of backlash. We cannot discriminate between each of these, but we demonstrate the force of mobility restrictions and the role of female job loss.

Lifting lockdown leads to a complete reversal and, indeed, crime reports rise 10 per cent, exceeding baseline levels by 5.6 per cent, consistent with new demand (reflected in distress calls persisting at levels above baseline) added to pent-up demand.

\section{$4 \quad$ Mechanisms: mobility and employment}

We estimate dynamic impacts of lockdown entry and exit on mobility and employment. Then, using a shift-share instrument, we estimate the contribution of job loss to DV. ${ }^{12}$

\subsection{Mobility}

Using day $\times$ municipality data from cellphone records and the $\operatorname{DID}_{M}$ estimator, we obtain Figure 3, panels (a)-(b). Volatility in the series reflects that these are daily data. There is no evidence that munic-

\footnotetext{
11 The average effect is a 17 per cent decline and we cannot reject that this is equal to the effect of lockdown entry.

12 We have also analysed heterogeneous effects of lockdown entry and exit by measures of vulnerability of the municipality to COVID-19-related changes in mobility and employment. The results show clear differences in the impact of lockdown entry by vulnerability, with highly vulnerable municipalities displaying the largest increase in distress calls and the largest reduction in crime reporting. Regarding lockdown exit, we do not find clear differences by vulnerability.
} 
ipalities that went into lockdown exhibited larger voluntary declines in mobility before lockdown than municipalities that did not go into lockdown in the sample period. This is interesting in its own right and also supports the identifying assumption. The dynamic effects show that imposition of lockdown leads to a sharp drop in mobility of about 35 per cent, which persists but attenuates over the three months after, averaging at 22 per cent. This measures not the absolute mobility decline but the difference between areas that were and were not under lockdown. Lifting lockdown resulted in an uptick in mobility which is statistically significant by about day-10 and increases to day-50, after which it starts to drop off, though it remains 20 per cent higher than at baseline. That recovery was only partial, and it is consistent both with weekend restrictions remaining in place (evident in the spikes in the plot) and with infection rates only starting to fall, on average, five weeks after lockdown withdrawal. This ratchet effect in mobility lines up with the ratchet effect in distress calls, consistent with mobility being a mechanism by which lockdown impacted DV.

\subsection{Labour market outcomes}

Using month $\times$ municipality data on private formal sector employment from administrative records, we obtain the $\mathrm{DID}_{M}$ estimates in Figure 3, panels (c)-(f). Lockdown imposition leads to a sharp and increasing descent in male employment that averages at about 1.15 percentage points or 3.4 per cent. Lifting lockdown leads to partial recovery, but male employment remains 1.4 per cent below its baseline level. This ratchet effect matches the pattern for helpline calls, suggesting male employment as a mechanism, which we formalize in the next section. Impacts of lockdown on female employment are an order of magnitude smaller, and exiting lockdown appears to reverse any impact.

We also see a sharp increase in worker contract suspensions under the state furlough scheme (Figure A4). The displayed estimates average over men and women but are dominated by movements for men. Although furlough protects income relative to job loss, the total impact of lockdown on earnings uncertainty includes its impacts on job loss and contract suspension.

\subsection{Identifying the contribution of employment decline to the increase in DV}

We use a shift-share strategy to identify impacts of employment loss on DV. We then combine these with the identified estimates of impacts of lockdown on employment to estimate employment-mediated impacts of lockdown on DV. To complete the mechanism chain, we require an estimate of $\beta$ from:

$$
D V_{s t}=\alpha+\beta \text { Employment }_{s t}+\mu_{s}+\varphi_{t}+\varepsilon_{s t} .
$$

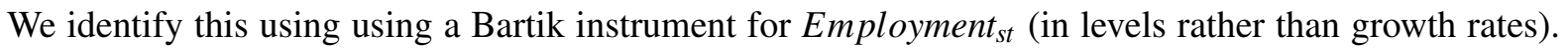
Following Card (2009) (discussed in Goldsmith-Pinkham et al. 2020, example 2), we define:

$$
B_{s t}=\sum_{k=1}^{K} z_{s 0 k} \times g_{k t},
$$

where $K$ indexes sector (Figure A5, shows sectoral differences in employment decline during COVID19). The instrument interacts municipality $s$ level baseline sectoral shares $\left(z_{s 0 k}\right)$ with aggregate sectorspecific employment rates $\left(g_{k t}\right)$. Specifically, $z_{s 0 k}=\left(N_{s 0 k} / N_{0 k}\right) \times\left(1 / P_{s, 2020}\right)$, where $N$ is number of workers by sector, $P$ is municipal population, $g_{k t}$ is total number of jobs lost between 2019 and 2020 in the country in sector $k$. The identifying assumption that baseline sector shares are uncorrelated with the COVID shock once we condition upon municipal and month FE seems reasonable.

Panel A of Table 1 shows shift-share estimates of Equation $2 .{ }^{13}$ We estimate that a one percentage point decrease in male employment increases distress calls by 25 per cent (by 1.3 relative to a mean of 4.8

${ }^{13}$ We do not provide results for shelters because shelter data are at region and not municipality level. 
per 100,000 individuals). Breaking this down, we see that male job loss triggers physical and psychological violence, with no significant impact on economic violence-for instance, a one-percentage-point decrease in male employment increases calls for physical violence by 37 per cent.

Female job loss has no significant impact on helpline calls but it reduces crime reporting (which is not sensitive to male job loss). This is consistent with male job loss resulting in a larger income shock and hence more stress, and with female job loss acting through the woman's participation constraint, making her less likely to report DV.

The direction of impacts is consistent with our main finding that lockdown (and associated job loss) led to increased distress calls and lower crime reporting. Panel B provides the summary estimates from Figure 2. Panel $\mathrm{C}$ implements the accounting exercise to determine the proportion of the full impact in Panel B that can be attributed to employment. We conclude that male employment loss accounts for 32.6 per cent of the increase in helpline calls. Female employment loss explains 6.5 per cent of the decrease in crime reporting. This share is small because lockdown has smaller impacts on female than on male employment.

\subsection{Discussion}

Pre-pandemic research on DV has been challenged by the fact that it is often difficult to disentangle incidence from reporting, and we have seen limited discussion of the problem in pandemic-based research, even though the pandemic (and lockdown) may directly affect reporting. Our finding that lockdown moves incidence and reporting in opposite directions highlights the relevance of this distinction.

Another consideration, neglected in the literature, is that lockdown may impact not only incidence but also tolerance levels. The mechanisms that we posit as driving impacts of lockdown can result in distress-evidence that lockdown has adversely influenced mental health (and more so among women) is provided in many recent studies, for example, Adams-Prassl et al. (in press), Etheridge and Spantig (2020), Giuntella et al. (2021). ${ }^{14}$

\subsection{Robustness checks}

We now discuss sensitivity checks on the estimates in Figures 2 and 3. We display $\mathrm{DID}_{M}$ estimates removing the COVID-19 controls in Figures A6 and A7. These estimates incorporate impacts that operate through lockdown changing COVID infection and testing rates. The placebo coefficients continue to be indistinguishable from zero, and the dynamic effects are larger-for example, for distress calls, they are 10 per cent larger. This is consistent with COVID indicators and lockdown tending to move helpline calls (and crime reports) in the same direction.

Direct impacts of COVID-19 infection rates on DV are in Table A4. A one-standard-deviation increase in COVID infection rates (an increase of 0.21 ) increases helpline calls by 1.1 per cent and decreases reporting by 0.08 per cent conditional on lockdown. The units of change are not comparable as lockdown is a binary event, but the direct impacts of infection rates are small relative to the impacts of lockdown conditional on infection rates. COVID positivity rates behave similarly to COVID infection rates conditional on test rates, and the direct impact of test rates is smaller and often not significant.

Event studies using the conventional DID estimator are shown in Figures A8 and A9. The corresponding single index coefficient estimates are in Table A4. Table A1 and Figure A10 present diagnostics to assess

14 An increasing number of women seeking refuge in public shelters is a hard outcome that very likely signals domestic violence. At the same time it is a stylized fact that many women put up with DV for a long time and often it takes a shock-such as lockdown - to act as the last straw. Any or all of unemployment, increased time with the partner at home, social isolation, and stress might trigger women to leave home or to seek helpline support. 
bias in the conventional estimator (de Chaisemartin and D'Haultfœuille 2020; Goodman-Bacon 2021). We find consistency across estimates that rely on comparison of treated municipalities with those treated earlier vs later vs never (Figure A10), and that negative weights sum to $<0.10$, often closer to zero. Given this, the broad patterns described by the conventional estimator agree with those documented using $\operatorname{DID}_{M}$.

Although the placebo effects shown in Figures 2 and 3 assuage the concern that lockdown mandates are correlated with underlying differences in trends in the outcomes prior to treatment, we present Rambachan and Roth (2021) bounds on the dynamic coefficients from the corresponding DiD event studies in Figures A11 and A12, accounting for (relatively small) pre-event deviations from parallel trends, as well as additional uncertainty in these deviations in the post-treatment period. The estimated bounds confirm the main findings, though the bounds widen with time from adoption given the accumulation of uncertainty.

\section{5}

\section{Policy remediation}

The national government introduced an emergency family income programme (Ingreso Familiar de Emergencia, IFE) in May 2020, providing cash transfers to low-income households most affected by the pandemic, with eligibility based on income, assets, and needs. Benefits comprised six payments between June and November 2020 of US\$80-130 per person for families without any formal income, while households with some formal income received a partial payment. We detail payment amounts and the number of beneficiaries for the payments made during the study period in Table A5. By the end of September, the state had spent over US $\$ 2,223$ million in emergency payments, 0.79 per cent of 2019 GDP. ${ }^{15}$ The trend in roll-out is in Figure A13a, showing that by September 2020 stimulus payments had reached nearly 8 million individuals, 42 per cent of the population. Figure A13b shows the distribution of payments, confirming widespread exposure to IFE.

We investigate whether IFE mitigated impacts of lockdown mandates on DV. If it did, this would constitute evidence that economic stress is a mechanism by which lockdown mandates impact DV, at least among low-income households who were the beneficiaries of the programme. ${ }^{16}$

We define the variable $I F E_{c t}$ as the proportion of the municipal population who received an IFE payment, with baseline variation in the proportion eligible being absorbed by municipality FE. This proportion is initially fixed at zero, and it jumps discontinuously with the first payment. As we are interested in modelling an interaction term, we use the single coefficient model, having shown diagnostics that suggest any potential bias is small. We estimate:

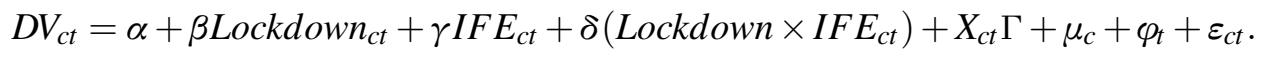

The parameter $\gamma$ measures the baseline impact of the policy, corresponding to the full impact in municipality-months not under lockdown. The impact of the policy in municipality-months under lockdown is given by $\gamma$ plus $\delta$. Municipality FE absorb the impacts of all fixed or slowly evolving factors like poverty, and time FE capture generic impacts of the pandemic across municipalities. As in the main

15 For comparison,the first stimulus payment under the CARES act in the US amounted to 1.36 per cent of 2019 US GDP, a total of 162 million payments that cost US\$292 billion.

${ }^{16}$ Chile also introduced contract suspension or furlough, for which only formal-sector workers paying into an unemployment insurance scheme were eligible. Data on this scheme are released annually and the available data run to 30 June 2020. During March-June 2020, 800,000 workers were on furlough. Thus, it had much lower coverage than IFE. We investigated if furlough protection had a mitigating effect, but the estimates are imprecise. 
analysis, we consistently control for the three COVID-19 indicators, and examine estimates that do not include these controls.

A potential concern with our specification is that, conditional upon all controls, exposure to IFE is not quasi-random. In particular, if municipalities with higher shares of IFE beneficiaries already had DV incidence declining more rapidly than municipalities with lower shares, then we might spuriously attribute changes in DV to IFE. To assess this concern, we regress lagged DV on IFE shares, using a series of lags for pre-COVID months (or, in the case of shelters, days). We do this for each of the three measures of DV, conditional upon the baseline controls. Figure A14 reports contemporaneous estimates (top row) and placebo coefficients. The placebos are, in general, small and insignificant. There is thus no evidence that municipalities with higher IFE shares had larger (or smaller) changes in DV pre-COVID. ${ }^{17}$

Table 2 presents the estimates, with all variables standardized as z-scores for ease of comparison. Unstandardized estimates are in panel A, Table A6. We see that stimulus payments mitigate impacts of lockdown on all three measures of DV. They reduce impacts of lockdown on helpline calls by a bit more than 50 per cent, reduce shelter use by more than lockdown increases it and, they increase crime reports by more than lockdown decreases them. IFE lowers DV irrespective of lockdown status, having larger impacts under lockdown only for helpline calls. These results are just slightly larger if we do not condition on the COVID variables (panel B, Table A6). In the only other paper attempting to analyse pandemic-specific policies on DV outcomes, Erten et al. (2021) also find evidence consistent with mitigation. Their effect sizes are not comparable because they use a dummy for the national timing of the introduction of stimulus payments, while we use variation in programme intensity by sub-region.

\section{Conclusions}

There is a long history of quarantines being imposed to prevent the spread of disease, dating back to the plagues in Europe and Asia in the Middle Ages (Adda 2016). This paper investigates impacts of lockdown (mass quarantine) on rates of domestic violence exposure and reporting in Chile using administrative data. We leverage the unusual policy environment in Chile where lockdown entry and exit were staggered across hundreds of municipalities, creating considerable variation in exposure within the same country, region, and even city. Using state-of-the-art observational techniques, we estimate dynamic effects of lockdown. We estimate impacts of both lockdown entry and exit, and we identify mechanisms.

We find that lockdown exacerbates DV, reinforcing the direct impacts of COVID-19, and that its impacts persist after lockdown is lifted. Our analysis of mechanisms indicates that job loss plays a role, with male and female job loss triggering changes in incidence and reporting, respectively. Consistent with job loss constituting an income shock, income support programmes mitigate the effect. The analysis reveals mechanisms - job loss and exposure - that are of broader relevance to understanding DV, even outside pandemic conditions.

\footnotetext{
17 The placebo effects are similar to pre-event coefficients in an event study. The current model is not amenable to this because IFE is continuous and interacted with lockdown.
} 


\section{References}

Adams-Prassl, A., Boneva, T., Golin, M., and Rauh, C. (2020). 'Inequality in the Impact of the Coronavirus Shock: Evidence from Real Time Surveys'. Journal of Public Economics, 189(-): 104245. https://doi.org/10.1016/j.jpubeco.2020.104245

Adams-Prassl, A., Boneva, T., Golin, M., and Rauh, C. (in press). 'The Impact of the Coronavirus Lockdown on Mental Health: Evidence from the US'. Economic Policy,(): .

Adda, J. (2016). 'Economic Activity and the Spread of Viral Diseases: Evidence from High Frequency Data'. The Quarterly Journal of Economics, 131(2): 891-941. https://doi.org/10.1093/qje/qjw005

Agüero, J. M. (2021). 'COVID-19 and the Rise of Intimate Partner Violence'. World Development, 137(C): 105217. https://doi.org/10.1016/j.worlddev.2020.105217

Alvarez, F., Argente, D., and Lippi, F. (2021). 'A Simple Planning Problem for COVID-19 Lock-down, Testing, and Tracing'. American Economic Review: Insights, 3(3): 367-82. https://doi.org/10.1257/aeri.20200201

Anderberg, D., Rainer, H., and Siuda, F. (2020). 'Quantifying Domestic Violence in Times of Crisis'. CESifo Working Paper 8539. Munich: CESifo. Available at: https://www.cesifo.org/node/58590 (accessed in January 2021)

Arenas-Arroyo, E., Fernandez-Kranz, D., and Nollenberger, N. (2021). 'Intimate Partner Violence under Forced Cohabitation and Economic Stress: Evidence from the COVID-19 Pandemic'. Journal of Public Economics, 194(-): 104350. https://doi.org/10.1016/j.jpubeco.2020.104350

Asik, G. A., and Nas Ozen, E. (2021). 'It Takes a Curfew: The Effect of Covid-19 on Female Homicides'. Economics Letters, 200(-): 109761. https://doi.org/10.1016/j.econlet.2021.109761

Autor, D. H. (2003). 'Outsourcing at Will: The Contribution of Unjust Dismissal Doctrine to the Growth of Employment Outsourcing'. Journal of Labor Economics, 21(1): 1-42. https://doi.org/10.1086/344122

Beland, L.-P., Brodeur, A., Haddad, J., and Mikola, D. (2020, June). 'Determinants of Family Stress and Domestic Violence: Lessons from the COVID-19 Outbreak'. Carleton Economic Papers 20-09. Carleton University, Department of Economics. Available at: https://ideas.repec.org/p/car/carecp/20-09.html (accessed in January 2021)

Berniell, I., and Facchini, G. (2021). 'COVID-19 Lockdown and Domestic Violence: Evidence from Internet-Search Behavior in 11 Countries'. European Economic Review, 136(-): 103775. https://doi.org/10.1016/j.euroecorev.2021.103775

Bhalotra, S., Britto, D. G. C., Pinotti, P., and Sampaio, B. (2021). 'Job Displacement, Unemployment Benefits and Domestic Violence'. CESifo Working Paper 9186. Munich: CESifo. Available at: https://ideas.repec.org/ p/ces/ceswps/_9186.html (accessed in September 2021)

Bravo, L., and Ferres, L. (2020). 'The IM (Mobility Index) Dataset'. Electronic Dataset. UDD and Ministry of Science, Chile.

Bullinger, L. R., Carr, J. B., and Packham, A. (2020). 'COVID-19 and Crime: Effects of Stay-at-Home Orders on Domestic Violence'. NBER Working Paper 27667. Cambridge, MA: National Bureau of Economic Research. https://doi.org/10.3386/w27667

Cajner, T., Crane, L. D., Decker, R. A., Grigsby, J., Hamins-Puertolas, A., Hurst, E., Kurz, C., and Yildirmaz, A. (2020). 'The U.S. Labor Market during the Beginning of the Pandemic Recession'. NBER Working Paper 27159. Cambridge, MA: National Bureau of Economic Research. https://doi.org/10.3386/w27159

Card, D. (2009, May). 'Immigration and Inequality'. American Economic Review, 99(2): 1-21. https://doi.org/10.1257/aer.99.2.1

Chalfin, A., Danagoulian, S., and Deza, M. (2021). 'COVID-19 Has Strengthened the Relationship Between Alcohol Consumption and Domestic Violence'. NBER Working Paper 28523. Cambridge, MA: National Bureau of Economic Research. https://doi.org/10.3386/w28523

de Chaisemartin, C., and D'Haultfœuille, X. (2020). 'Two-Way Fixed Effects Estimators with Heterogeneous Treatment Effects'. American Economic Review, 110(9): 2964-96. https://doi.org/10.1257/aer.20181169

Eichenbaum, M. S., Rebelo, S., and Trabandt, M. (2021). 'The Macroeconomics of Epidemics'. The Review of Financial Studies, 34(11): 5149-87. https://doi.org/10.1093/rfs/hhab040

Erten, B., Keskin, P., and Prina, S. (2021). Social Distancing, Stimulus Payments, and Domestic Violence: Evidence from the U.S. during COVID-19 [unpublished paper].

Etheridge, B., and Spantig, L. (2020). 'The Gender Gap in Mental Well-Being During the Covid-19Outbreak: Evidence from the UK'. ISER Working Paper 2020-08. Colchester: Institute for Social and Economic Research (ISER), University of Essex. Available at: http://hdl.handle.net/10419/227789

Farboodi, M., Jarosch, G., and Shimer, R. (2021). 'Internal and External Effects of Social Distancing in a Pandemic'. Journal of Economic Theory, 196(-): 105293. https://doi.org/10.1016/j.jet.2021.105293 
Farré, L., Fawaz, Y., González, L., and Graves, J. (2020). 'How the COVID-19 Lockdown Affected Gender Inequality in Paid and Unpaid Work in Spain'. IZA Discussion Paper 13434. Bonn: Institute of Labor Economics (IZA).

Gibbons, M. A., Murphy, T. E., and Rossi, M. A. (2020). 'Confinement and Intimate Partner Violence: The ShortTerm Effect of COVID-19'. IDB Technical Note 1956. Washington, DC: Inter-American Development Bank.

Giuntella, O., Hyde, K., Saccardo, S., and Sadoff, S. (2021). 'Lifestyle and Mental Health Disruptions during COVID-19'. Proceedings of the National Academy of Sciences, 118(9): e2016632118. https://doi.org/10.1073/pnas.2016632118

Goldsmith-Pinkham, P., Sorkin, I., and Swift, H. (2020, August). 'Bartik Instruments: What, When, Why, and How'. American Economic Review, 110(8): 2586-624. https://doi.org/10.1257/aer.20181047

Goodman-Bacon, A. (2021). 'Difference-in-Differences with Variation in Treatment Timing'. Journal of Econometrics, 225(2): 254-77. https://doi.org/10.1016/j.jeconom.2021.03.014

Hsu, L.-C., and Henke, A. (2021). 'COVID-19, Staying at Home, and Domestic Violence'. Review of Economics of the Household, 19(-): 145-55. https://doi.org/10.1007/s11150-020-09526-7

Ivandić, R., Kirchmaier, T., and Linton, B. (2020). 'Changing Patterns of Domestic Abuse during Covid-19 Lockdown'. CEP Discussion Paper 1729. London: Centre for Economic Performance.

Leslie, E., and Wilson, R. (2020). 'Sheltering in Place and Domestic Violence: Evidence from Calls for Service during COVID-19'. Journal of Public Economics, 189(-): 104241. https://doi.org/10.1016/j.jpubeco.2020.104241

Miller, A. R., Segal, C., and Spencer, M. K. (2020). 'Effects of the COVID-19 Pandemic on Domestic Violence in Los Angeles'. NBER Working Paper 28068. Cambridge, MA: National Bureau of Economic Research. https://doi.org/10.3386/w28068

Pappalardo, L., Cornacchia, G., Navarro, V., Bravo, L., and Ferres, L. (2020). A Dataset to Assess Mobility Changes in Chile Following Local Quarantines. Available at: https://arxiv.org/abs/2011.12162

Perez-Vincent, S. M., Carreras, E., Gibbons, M. A., Murphy, T. E., and Rossi, M. A. (2020). 'COVID-19 Lockdowns and Domestic Violence: Evidence from Two Studies in Argentina'. IDB Technical Note 1956. Washington, DC: Inter-American Development Bank.

Piquero, A. R., Riddell, J. R., Bishopp, S. A., Narvey, C., Reid, J. A., and Piquero, N. (2020). 'Staying Home, Staying Safe? A Short-Term Analysis of COVID-19 on Dallas Domestic Violence'. American Journal of Criminal Justice, 45(4): 601-35. https://doi.org/10.1007/s12103-020-09531-7

Rambachan, A., and Roth, J. (2021). 'An Honest Approach to Parallel Trends'. Working Paper. https:// asheshrambachan.github.io/assets/files/hpt-draft.pdf.

Ravindran, S., and Shah, M. (2020). 'Unintended Consequences of Lockdowns: COVID-19 and the Shadow Pandemic'. NBER Working Paper 27562. Cambridge, MA: National Bureau of Economic Research. https://doi.org/10.3386/w27562

Sanga, S., and McCrary, J. (2020). 'The Impact of the Coronavirus Lockdown on Domestic Violence'. Available at SSRN. https://doi.org/10.2139/ssrn.3612491

Silverio-Murillo, A., Balmori de la Miyar, J. R., and Hoehn-Velasco, L. (2020). 'Families under Confinement: COVID-19, Domestic Violence, and Alcohol Consumption'. Available at SSRN. https://doi.org/10.2139/ssrn.3688384

Sun, L., and Abraham, S. (2021). 'Estimating Dynamic Treatment Effects in Event Studies with Heterogeneous Treatment Effects'. Journal of Econometrics, 225(2): 175-99. (Themed Issue: Treatment Effect 1) https://doi.org/10.1016/j.jeconom.2020.09.006

Toxvaerd, F. (2020). 'Equilibrium Social Distancing'. Cambridge-INET Working Paper 2020/08. Cambridge: University of Cambridge. https://doi.org/10.17863/CAM.52489

UN Women (2020). 'COVID-19 and Ending Violence Against Women and Girls'. Briefing. New York: United Nations Entity for Gender Equality and the Empowerment of Women (UN Women). 


\section{Figures and tables}

Figure 1: Temporal dynamics of lockdown imposition and removal

(a) Ever locked down

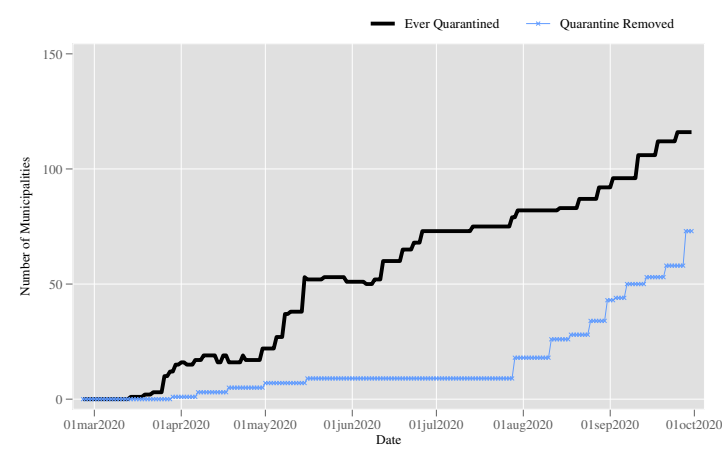

(b) Current lockdowns

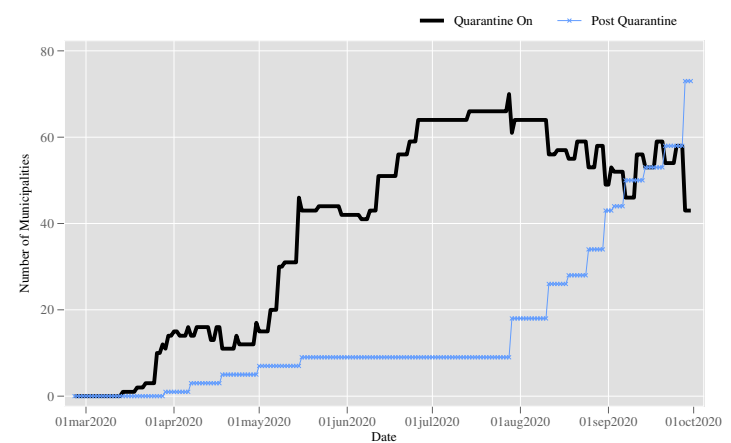

Note: panel (a) documents the accumulated number of municipalities ever locked down, and for which the lockdown has been subsequently removed. The total number of municipalities in Chile is 346, 116 of which entered into lockdown between 14 March and 30 September 2020. Panel (b) documents the total number of municipalities currently in or out of lockdown at a given moment of time between March and September 2020. A supplementary video file documenting the dynamic nature of lockdown imposition as well as the total population under lockdown in the Metropolitan Region of Santiago is available online at: https://bit.ly/3pUeULZ.

Source: authors' calculations based on data presented in Appendix B. 
Figure 2: Impacts of lockdown on incidence of intra-family violence

(a) Distress calls (entry)

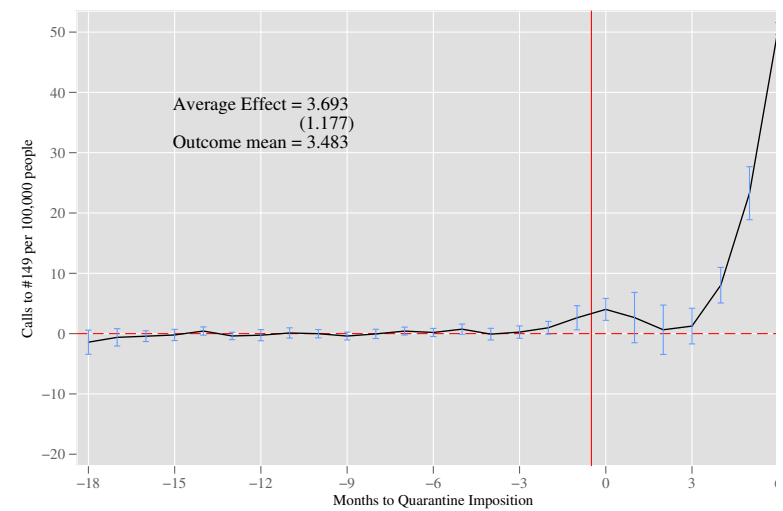

(c) Shelter usage (entry)

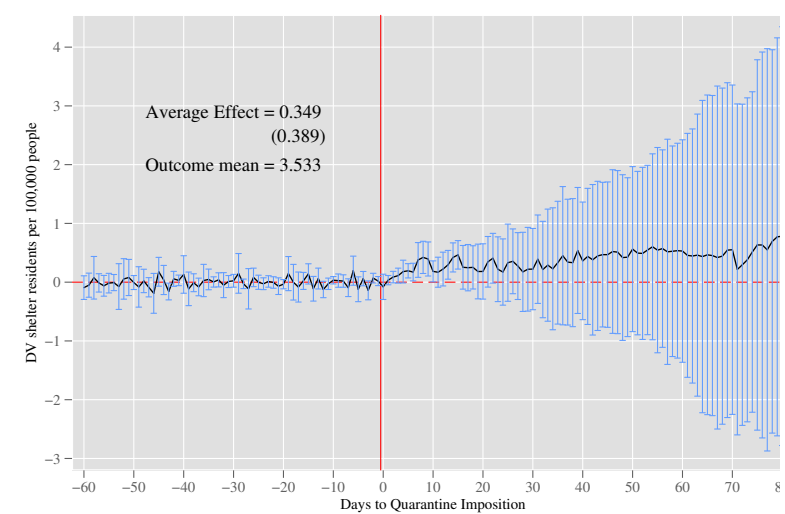

(e) Crime reporting (entry)

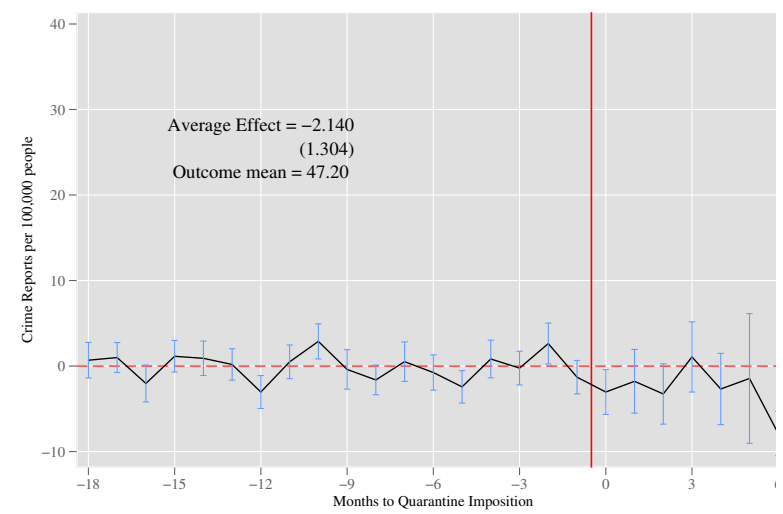

(b) Distress calls (exit)

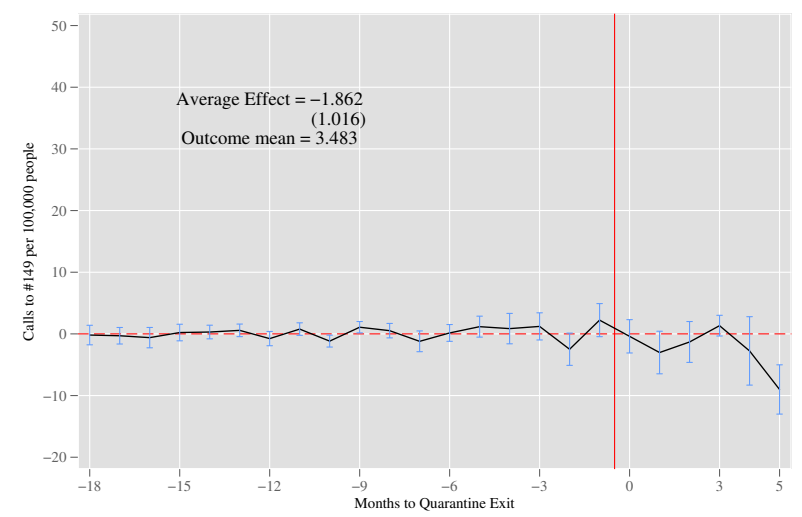

(d) Shelter usage (exit)

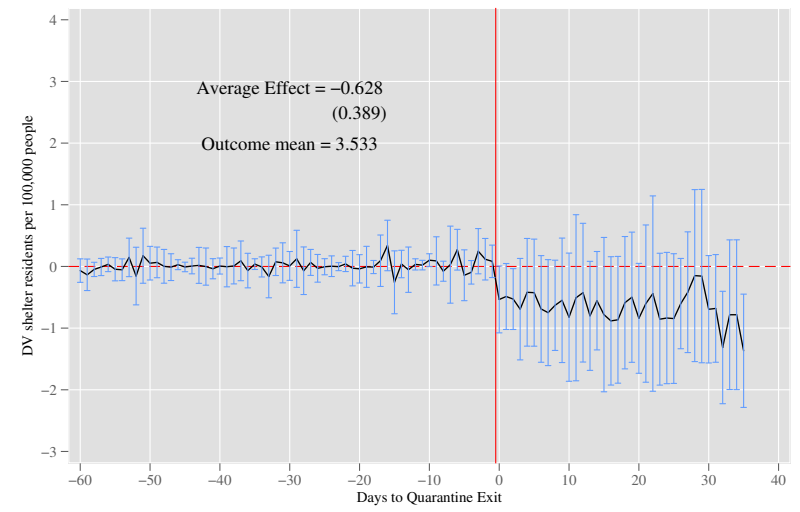

(f) Crime reporting (exit)

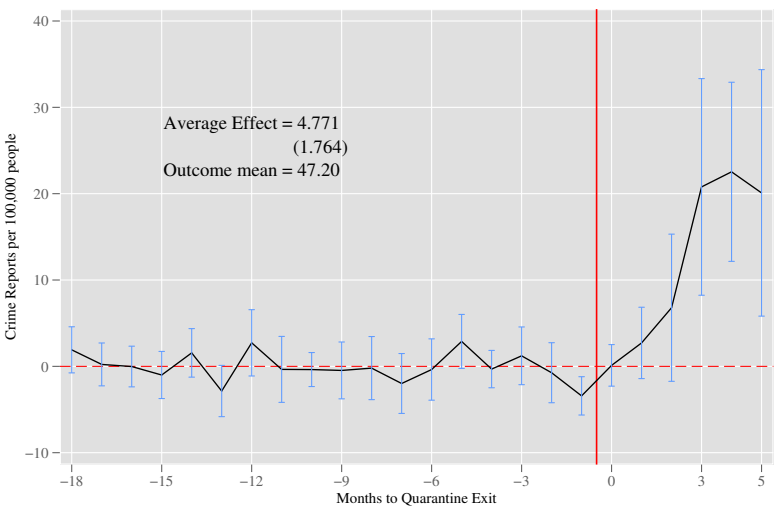

Note: point estimates and confidence intervals are displayed from the $D I D_{M}$ estimator documenting placebo (pre-event) and dynamic (post-event) impacts of lockdown imposition (left-hand panels) or removal (right-hand panels) on rates of calls to the Chilean police family support hotline (panels (a) and (b)), the population of individuals residing in government-run domestic violence shelters (panels (c) and (d)), and formal criminal complaints (panels (e) and (f)). The left-hand panel consists of all municipalities, where the event of interest refers to the imposition of lockdown (if the municipality has ever adopted). The right-hand panel consists of all municipalities which have ever entered lockdown (and hence could theoretically exit lockdown), where the event of interest refers to the removal of lockdown. In each case, controls for rates of COVID infection and testing are included. Specifications without controls are provided in supplementary materials, Appendix A, Figure A6. Confidence intervals are estimated using a block-bootstrap by municipality (panels (a), (b), (e), and (f)) or region (panels (c) and (d)). Source: authors' calculations based on data presented in Appendix B. 
Figure 3: Impacts of lockdown on mechanism variables (a) Cell phone mobility patterns (entry)

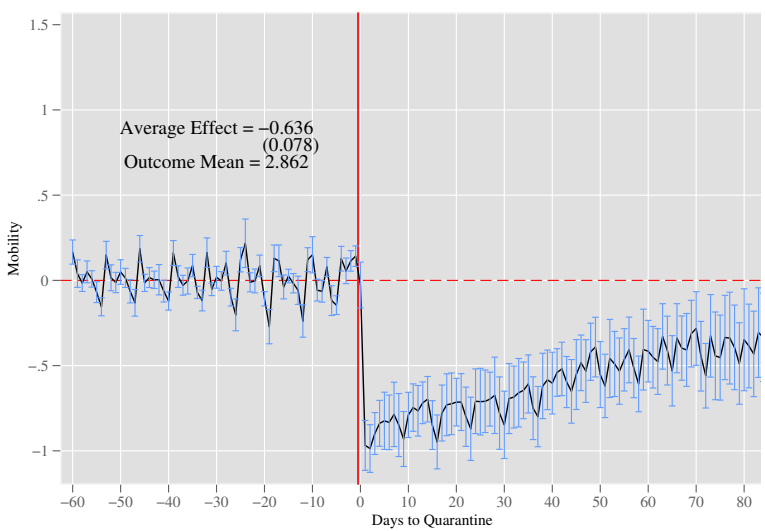

(c) Male formal employment rate (entry)

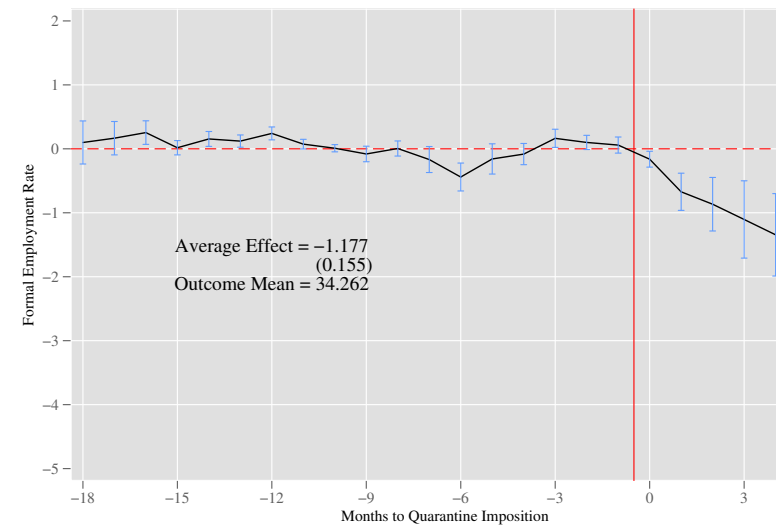

(e) Female formal employment rate (entry)

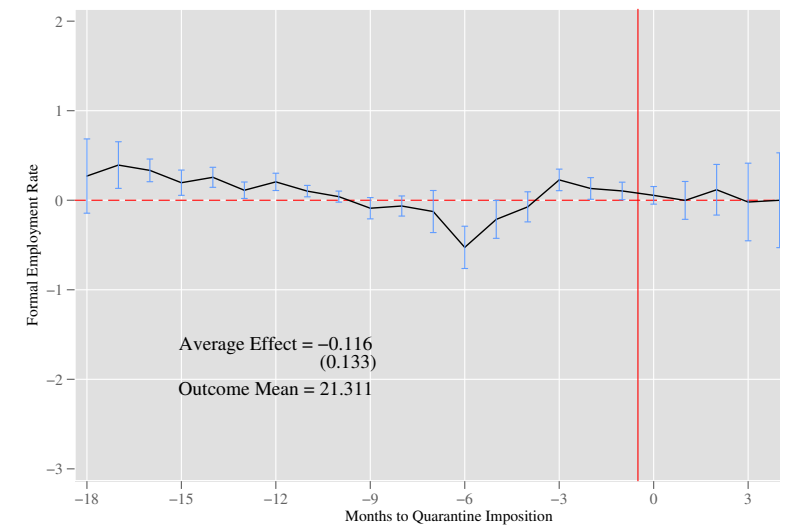

(b) Cell phone mobility patterns (exit)

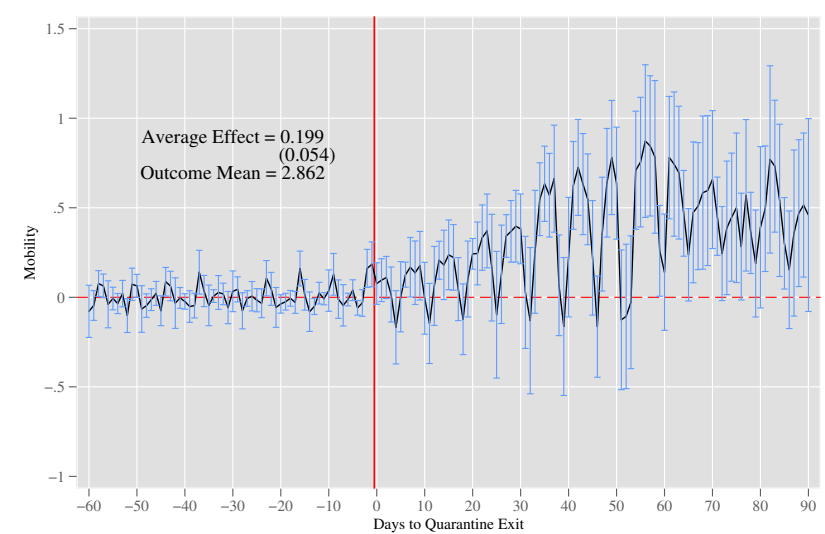

(d) Male formal employment rate (exit)

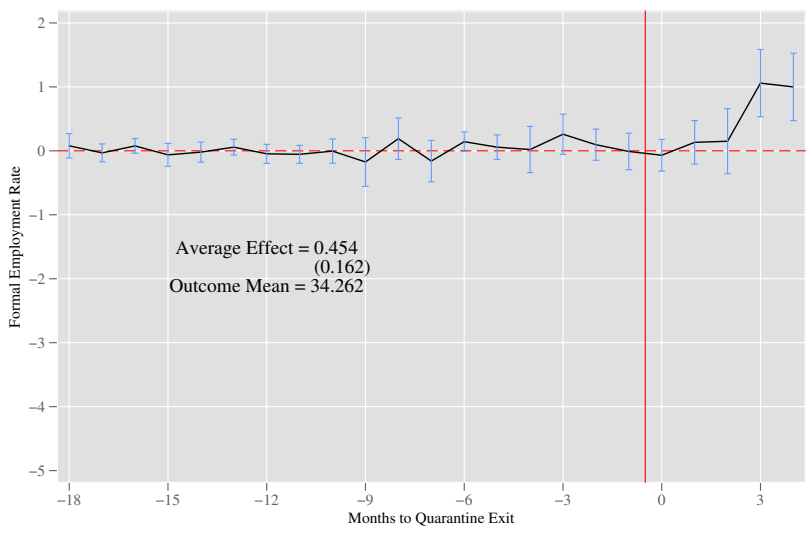

(f) Female formal employment rate (exit)

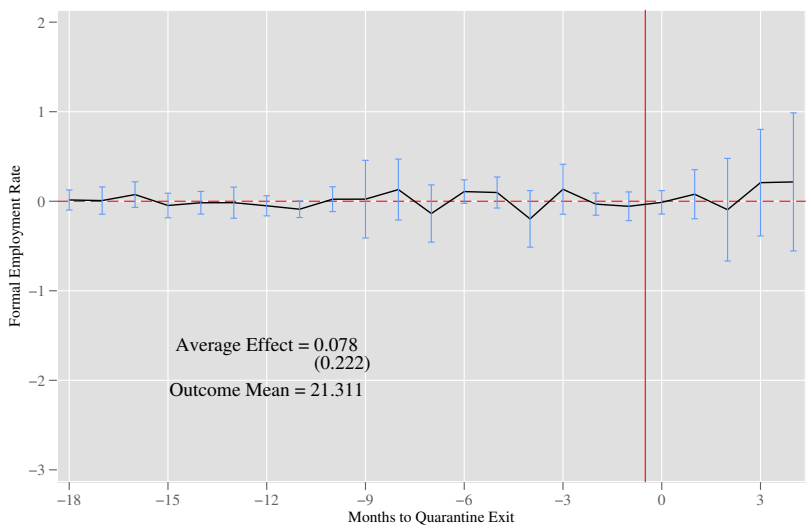

Note: refer to the note under Figure 2. Identical specifications are estimated, however examining mobility patterns based on within-municipality daily movement from cell phone data (panels (a) and (b)) and municipal-level employment rates in the formal private labour market from administrative records (panels $(c)$ to $(f)$ ). All other estimation details follow those indicated in the note under Figure 2.

Source: authors' calculations based on data presented in Appendix B. 
Table 1: Decomposing the contribution of gender-specific employment shocks to changes in domestic violence

\begin{tabular}{|c|c|c|c|c|c|}
\hline & \multicolumn{4}{|c|}{ Calls } & \multirow{2}{*}{$\begin{array}{c}\text { Crime } \\
\text { Reporting }\end{array}$} \\
\hline & All calls & Economic & Physical & Psychological & \\
\hline \multicolumn{6}{|l|}{ Panel A: Shift-share IV } \\
\hline \multirow[t]{2}{*}{ Formal employment (women) } & 0.442 & -0.0142 & 0.271 & 0.185 & 1.182 \\
\hline & $(0.587)$ & $(0.0166)$ & $(0.305)$ & $(0.330)$ & $(0.734)$ \\
\hline \multirow[t]{2}{*}{ Formal employment (men) } & $-1.227^{\star *}$ & 0.00170 & $-0.691^{* *}$ & $-0.537^{*}$ & -0.0518 \\
\hline & $(0.576)$ & $(0.0197)$ & $(0.334)$ & $(0.318)$ & $(0.783)$ \\
\hline Observations & 4,475 & 4,475 & 4,475 & 4,475 & 4,468 \\
\hline R-squared & 0.275 & 0.013 & 0.267 & 0.152 & 0.039 \\
\hline Mean dep. var. & 4.865 & 0.0299 & 1.849 & 2.986 & 45.52 \\
\hline First stage F-statistic (C.-D.) & 249 & 249 & 249 & 249 & 248.5 \\
\hline \multicolumn{6}{|c|}{ Panel B: Lockdown and domestic violence } \\
\hline Lockdown & $\begin{array}{c}3.393^{* * *} \\
(1.177)\end{array}$ & $\begin{array}{c}0.085^{* * *} \\
(0.036)\end{array}$ & $\begin{array}{c}1.911^{* * *} \\
(0.683)\end{array}$ & $\begin{array}{c}1.697^{* * *} \\
(1.304)\end{array}$ & $\begin{array}{c}-2.140^{* *} \\
(0.756)\end{array}$ \\
\hline \multicolumn{6}{|l|}{ Panel C: Scaled estimates } \\
\hline Mediator: women's job loss & $-1.2 \%$ & $1.9 \%$ & $-1.6 \%$ & $-1.3 \%$ & $6.5 \%$ \\
\hline Mediator: ,en's job loss & $32.6 \%$ & $-4.7 \%$ & $42.6 \%$ & $37.2 \%$ & $-2.9 \%$ \\
\hline
\end{tabular}

Note: decompositions of the contributions of job loss to observed impacts of lockdown on domestic violence distress calls (columns 1 to 4) and crime reporting (column 5) are presented. These scaled estimates (panel C) provide estimates of the proportion of the total impact of lockdown on domestic violence (panel B) which can be explained by the estimated direct impact of formal employment changes on rates of domestic violence (panel A), interacted with the actual rates of job loss observed due to lockdown imposition. These rates of job loss are estimated in Figure $3 \mathrm{c}$ and $3 \mathrm{e}$ for men and women, respectively. Source: authors' calculations based on data presented in Appendix B. 
Table 2: Stimulus payments, lockdown, and domestic violence

\begin{tabular}{|c|c|c|c|c|c|c|}
\hline & \multicolumn{2}{|c|}{ Calls to 149} & \multicolumn{2}{|c|}{ Crime reporting } & \multicolumn{2}{|c|}{ Shelter residence } \\
\hline & (1) & $(2)$ & (3) & $(4)$ & (5) & (6) \\
\hline Lockdown & $\begin{array}{l}0.114^{\star * *} \\
(0.0181)\end{array}$ & $\begin{array}{l}0.147^{* \star *} \\
(0.0247)\end{array}$ & $\begin{array}{l}-0.00802^{* *} \\
(0.00323)\end{array}$ & $\begin{array}{l}-0.00486 \\
(0.00461)\end{array}$ & $\begin{array}{c}0.0315 \\
(0.0401)\end{array}$ & $\begin{array}{c}0.0376 \\
(0.0418)\end{array}$ \\
\hline IFE & $\begin{array}{l}-0.0359 \\
(0.0447)\end{array}$ & $\begin{array}{l}-0.0262 \\
(0.0435)\end{array}$ & $\begin{array}{l}0.0412^{\star \star \star} \\
(0.0118)\end{array}$ & $\begin{array}{c}0.0428^{* * *} \\
(0.0111)\end{array}$ & $\begin{array}{l}-0.256^{\star} \\
(0.140)\end{array}$ & $\begin{array}{l}-0.255^{\star} \\
(0.142)\end{array}$ \\
\hline Lockdown $\times$ IFE & & $\begin{array}{c}-0.0469^{\star *} \\
(0.0227)\end{array}$ & & $\begin{array}{l}-0.00443 \\
(0.00481)\end{array}$ & & $\begin{array}{r}-0.00967 \\
(0.0331)\end{array}$ \\
\hline $\begin{array}{l}\text { Joint estimate } \\
\text { IFE + }\end{array}$ & & & & & & \\
\hline lockdown $\times$ IFE & & $\begin{array}{l}-0.073 \\
(0.058)\end{array}$ & & $\begin{array}{c}0.038^{\star \star \star} \\
(0.013)\end{array}$ & & $\begin{array}{l}-0.264^{*} \\
(0.140)\end{array}$ \\
\hline Observations & 7,262 & 7,262 & 26,915 & 26,915 & 4,128 & 4,128 \\
\hline R-squared & 0.784 & 0.785 & 0.560 & 0.560 & 0.856 & 0.856 \\
\hline
\end{tabular}

Note: each column regresses measures of DV incidence or reporting on time-varying receipt of IFE stimulus payments, which began in May 2020 and further rolled out to broader populations thereafter. IFE refers to the proportion of the municipal (columns 1-4) or regional (columns 5-6) population receiving transfers. Lockdown $\times$ IFE interacts each municipality's lockdown status with the proportion of IFE receipt. All regressions include geographic and time fixed effects and cluster standard errors by area. Outcome variables and independent variables are standardized as a z-score for ease of comparison of coefficients. 'Joint estimate' refers to the linear combination of the parameters on IFE and lockdown $\times$ IFE along with the standard error of this combination, reported in columns where interactions are considered. ${ }^{* *} p<0.01,{ }^{* *} p<0.05,{ }^{*} p<0.1$.

Source: authors' calculations based on data presented in Appendix B. 


\section{Appendix: supplementary material}

\section{A Appendix figures and tables}

Table A1: Negative weights in two-way fixed-effect models

\begin{tabular}{lccc}
\hline & $\begin{array}{c}\text { Number } \\
g, t\end{array}$ & $\begin{array}{c}\text { Number } \\
\text { negative } g, t\end{array}$ & $\begin{array}{c}\text { Total sum of } \\
\text { negative weights }\end{array}$ \\
\hline $\begin{array}{l}\text { Lockdown entry } \\
\text { Distress Calls }\end{array}$ & 334 & 7 & -0.0046 \\
Police Reporting & 334 & 1 & -0.0007 \\
Shelters & 1580 & 264 & -0.0971 \\
& & & \\
\hline Lockdown exit & & & - \\
Distress Calls & 130 & 0 & - \\
Police Reporting & 130 & 0 & - \\
$\quad$ Shelters & 132 & 0 & \\
& & & \\
\hline
\end{tabular}

Note: the number of group $\times$ time specific estimates are displayed, as well as the number of units receiving negative weights, following de Chaisemartin and D'Haultfœuille (2020). Each $g, t$ group refers to treatment effects in municipalities which adopted at a specific time, in a specific post treatment year $t$. A full decomposition of the two-way fixed-effect estimator for lockdown entry in models based on municipal data is provided in Figure A10.

Source: authors' calculations based on data presented in Appendix B.

Figure A1: Calls to DV hotline-2019 vs 2020

(a) January and February (pre): $<100$ Calls

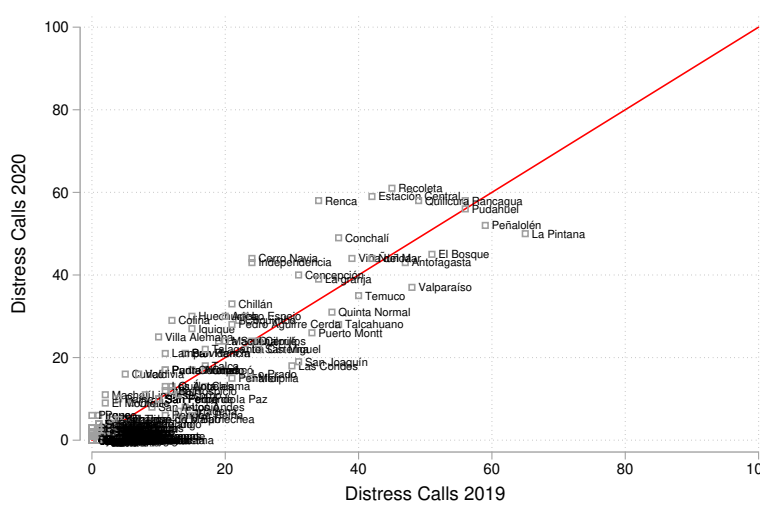

(b) April-June (post) $<100$ Calls

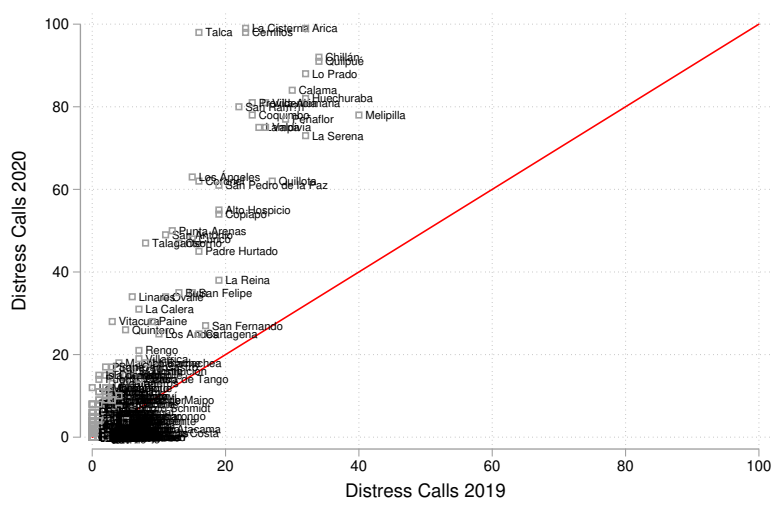

Note: panel (a) presents a plot of municipalities by the number of calls to the police DV hotline in January and February 2019 (x-axis) and 2020 (y-axis). Panel (b) presents a plot of municipalities by the number of calls to the DV hotline in April-June 2019 (x-axis) and 2020 (y-axis). In both panels we have excluded municipalities with more than 100 calls per month for ease of visualization.

Source: authors' calculations based on data presented in Appendix B. 
Figure A2: Criminal complaints for intra-family violence-2019 vs 2020

(a) January-February (pre): <200 Complaints

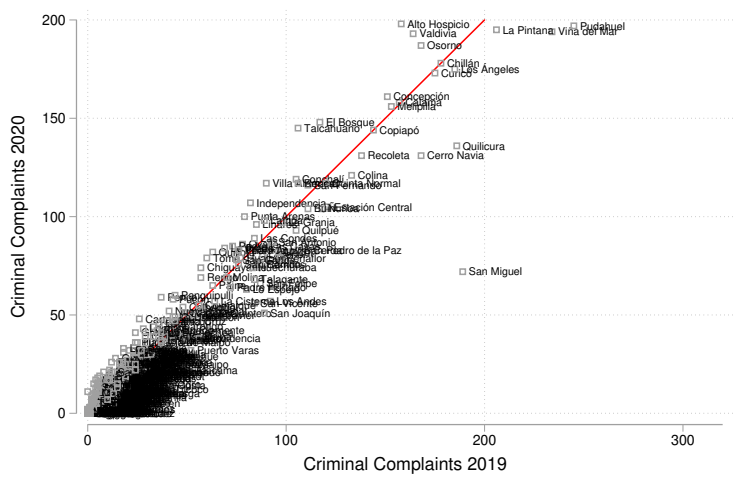

(b) April-June (post) $<200$ Complaints

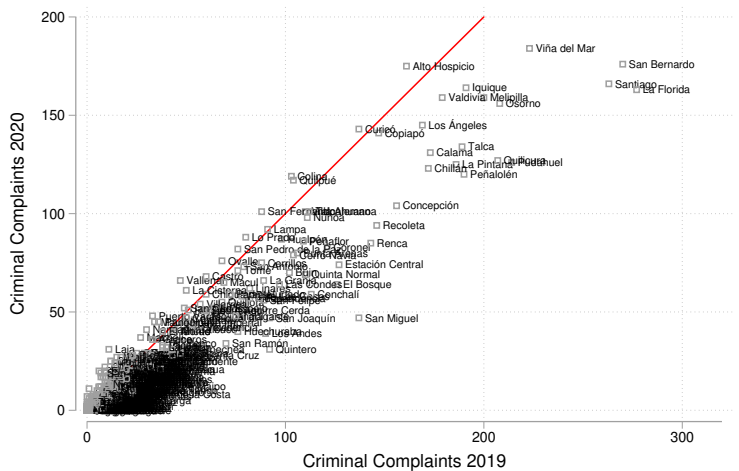

Note: panel (a) presents a plot of municipalities by the number of criminal complaints for intra-family violence lodged in January and February 2019 (x-axis) and 2020 (y-axis). Panel (b) presents a plot of municipalities by the number of criminal complaints for intra-family violence lodged in April-June 2019 (x-axis) and 2020 (y-axis). In both panels we have excluded municipalities with more than 200 complaints per month for ease of visualization.

Source: authors' calculations based on data presented in Appendix B.

Table A2: Proportion of municipalities and population driving estimates

\begin{tabular}{lcclccc}
\hline & \multicolumn{2}{c}{ Lockdown imposition } & & \multicolumn{2}{c}{ Lockdown exit } \\
\cline { 2 - 3 } \cline { 5 - 6 } Time period & Municipalities & Population & & Municipalities & Population \\
\hline 0 & 128 & 16079843 & & 43 & 5412691 \\
1 & 91 & 13598284 & & 18 & 1864586 \\
2 & 59 & 10478789 & & 9 & 692228 \\
3 & 41 & 7274131 & & 9 & 692228 \\
4 & 27 & 4962373 & & 7 & 600991 \\
5 & 7 & 1680245 & & - & - \\
6 & 1 & 89493 & & - & - \\
\hline
\end{tabular}

Note: $D I D_{M}$ dynamic (post-lockdown) effects are based on municipalities which have entered lockdowns and been in lockdown for at least $x$ months (or exited lockdowns and been out of lockdowns for $x$ months in the case of lockdown exit), where $x$ refers to the time period indicated on the horizontal axis of the $D I D_{M}$ result graph. As lockdown length varies by municipality, estimates of varying length are driven by different sub-groups of municipalities. The sub-groups having had at least 0-6 months of lockdown are indicated in the left-hand panel, and the sub-groups having had at least 0-4 months out of lockdown are indicated on the right-hand panel.

Source: authors' calculations based on data presented in Appendix B. 
Table A3: Aggregate $D I D_{M}$ estimates of lockdown imposition and removal on distress calls by type of violence

\begin{tabular}{|c|c|c|c|c|c|c|c|c|}
\hline & \multicolumn{2}{|c|}{ All calls } & \multicolumn{2}{|c|}{ Physical violence } & \multicolumn{2}{|c|}{ Psychological violence } & \multicolumn{2}{|c|}{ Economic violence } \\
\hline & (1) & (2) & (3) & (4) & (5) & (6) & (7) & (8) \\
\hline Lockdown imposed & $\begin{array}{c}4.299^{* * *} \\
(1.107)\end{array}$ & $\begin{array}{c}3.693^{* * *} \\
(1.177)\end{array}$ & $\begin{array}{c}2.893^{* * *} \\
(0.683)\end{array}$ & $\begin{array}{c}2.205^{* * *} \\
(0.727)\end{array}$ & $\begin{array}{l}1.397^{* *} \\
(0.672)\end{array}$ & $\begin{array}{l}1.814^{* *} \\
(0.749)\end{array}$ & $\begin{array}{c}0.042 \\
(0.029)\end{array}$ & $\begin{array}{l}0.077^{* *} \\
(0.031)\end{array}$ \\
\hline Lockdown removed & $\begin{array}{c}-1.996^{*} \\
(1.246)\end{array}$ & $\begin{array}{c}-1.862^{*} \\
(1.016)\end{array}$ & $\begin{array}{c}-1.622^{* * *} \\
(0.479)\end{array}$ & $\begin{array}{l}-0.379 \\
(0.622)\end{array}$ & $\begin{array}{c}-1.659^{* *} \\
(0.723)\end{array}$ & $\begin{array}{l}-0.467 \\
(0.828)\end{array}$ & $\begin{array}{l}-0.006 \\
(0.034)\end{array}$ & $\begin{array}{c}0.000 \\
(0.042)\end{array}$ \\
\hline Observations & 7,266 & 7,266 & 7,266 & 7,266 & 7,266 & 7,266 & 7,266 & 7,266 \\
\hline Baseline mean & 3.483 & 3.483 & 1.283 & 1.283 & 2.185 & 2.185 & 0.015 & 0.015 \\
\hline COVID-19 controls & & Y & & Y & & $\mathrm{Y}$ & & Y \\
\hline
\end{tabular}

Note: each column displays aggregate $D I D_{M}$ estimates of impacts of lockdown imposition and removal on DV distress calls by type of violence as classified by police telephone operators. Columns 1-2 replicate results using all calls (as in Figure 2), while columns 3-8 break this down by each violence type. Aggregate $D I D_{M}$ estimates are presented weighting by the number of affected individuals at each lag. Standard errors are estimated using a blocked bootstrap clustered by municipality. ${ }^{* \star *},{ }^{* *}$, and * indicate statistical significance at the $1 \%, 5 \%$, and $10 \%$, respectively.

Source: authors' calculations based on data presented in Appendix B.

Figure A3: Lockdown imposition and removal and supported spots at DV shelters

(a) Lockdown entry

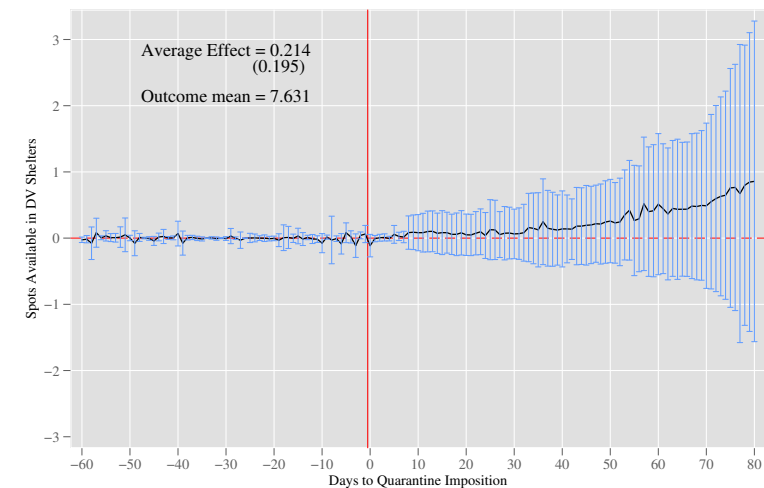

(b) Lockdown exit

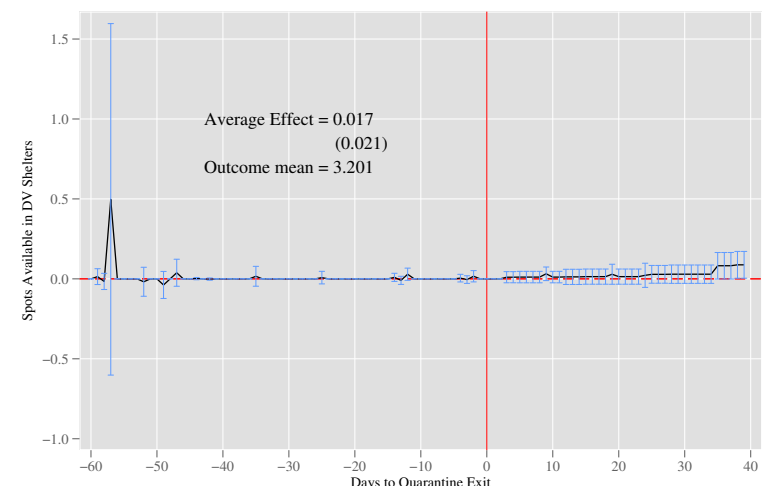

Note: refer to the note under Figure 2. Identical specifications are estimated, however examining available spots at DV shelters. All other estimation details follow those indicated in the note under Figure 2.

Source: authors' calculations based on data presented in Appendix B.

Figure A4: Lockdown imposition and removal and job suspensions

(a) Lockdown entry

(b) Lockdown exit
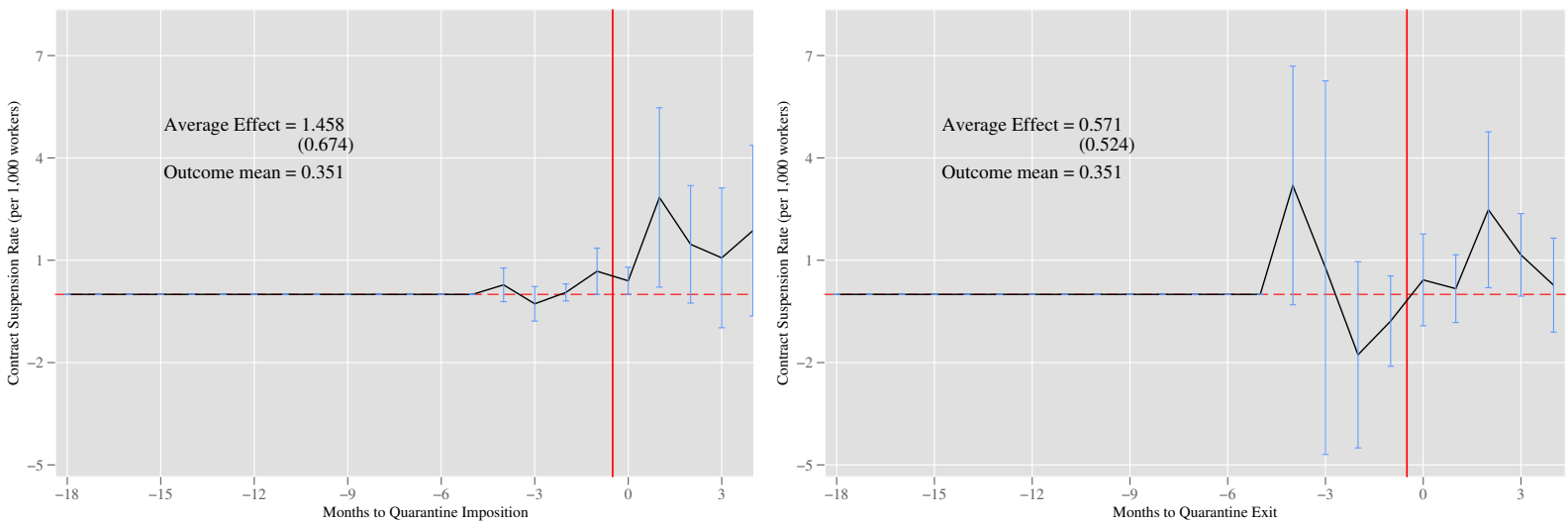

Note: refer to the note under Figure 2. Identical specifications are estimated, however examining contract suspensions. All other estimation details follow those indicated in the note under Figure 2.

Source: authors' calculations based on data presented in Appendix B. 
Figure A5: Sectoral trends in employment by gender (total employment)
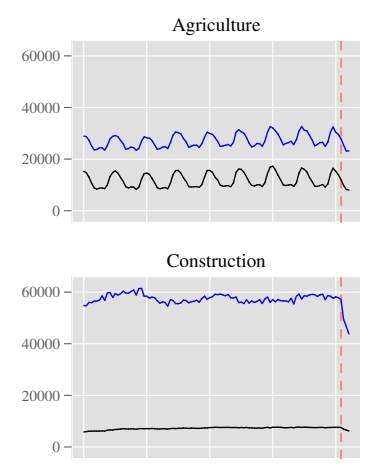

Financial Services

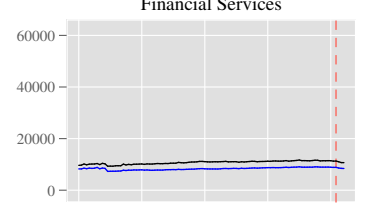

Teaching

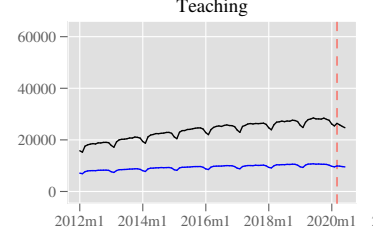

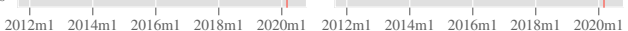

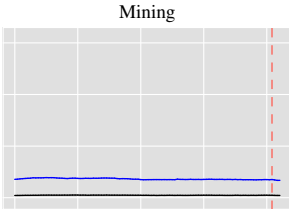

Sales

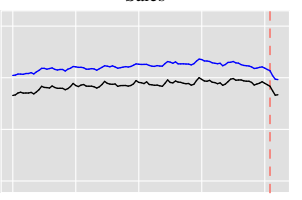

Real Estate

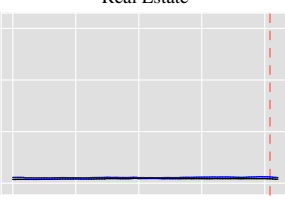

Healthcare

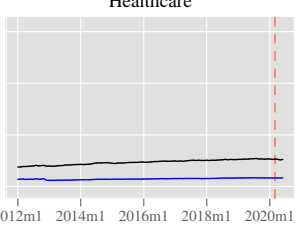

Manufacturing

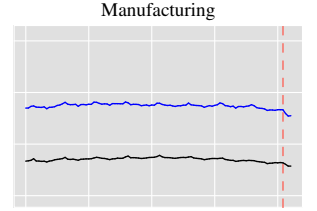

Transport

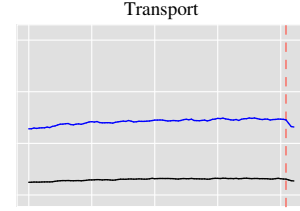

Science

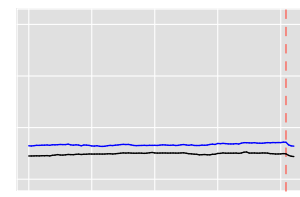

Artistic Activities

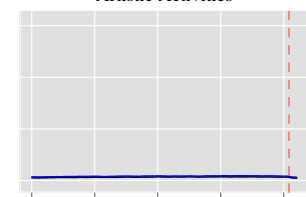

Electricity Provision

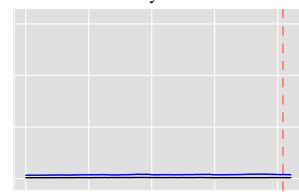

Hospitality

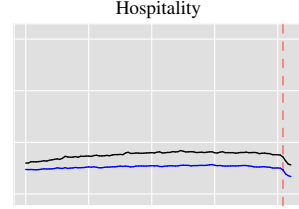

Administrative Services

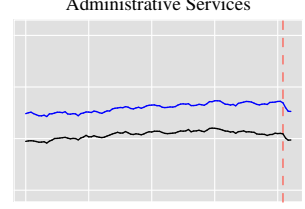

Other

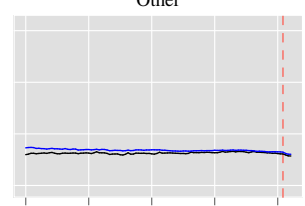

Water Provision

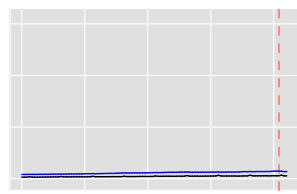

Comunications

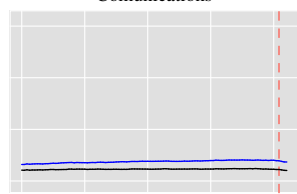

Public Administration

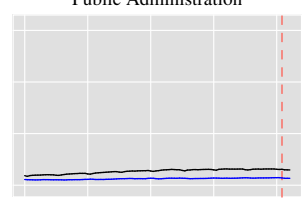

Extraterritorial activities

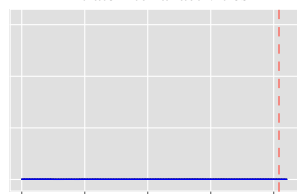

Note: data from a $12 \%$ sample of the universe of formal private workers is displayed as reported in the country's unemployment insurance database. The total number of workers in each employment class is displayed.

Source: authors' calculations based on data presented in Appendix B. 
Figure A6: Impacts of lockdown on incidence of intra-family violence (no COVID controls)

(a) Distress calls (entry)

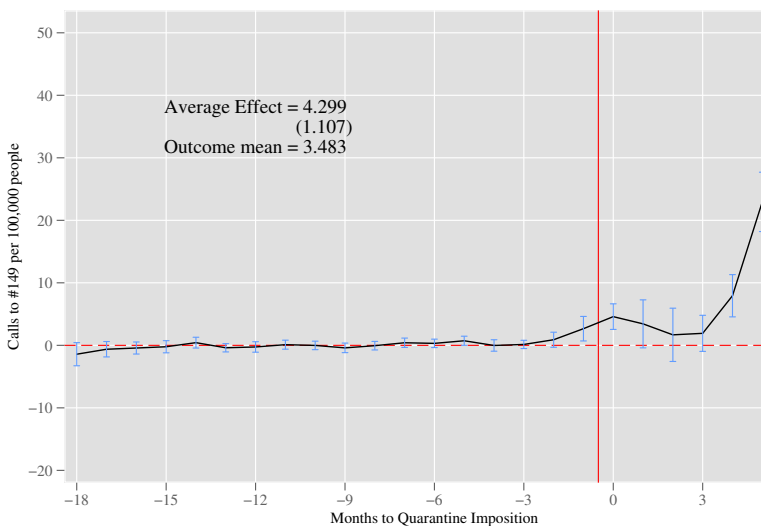

(c) Shelter usage (entry)

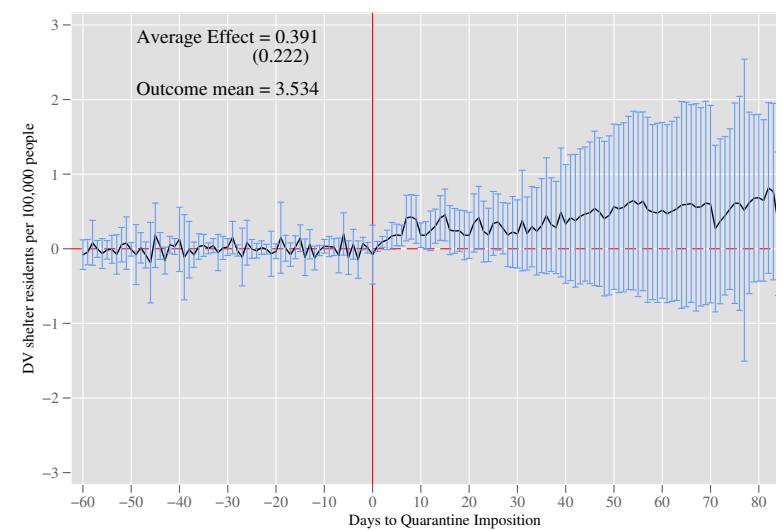

(e) Crime reporting (entry)

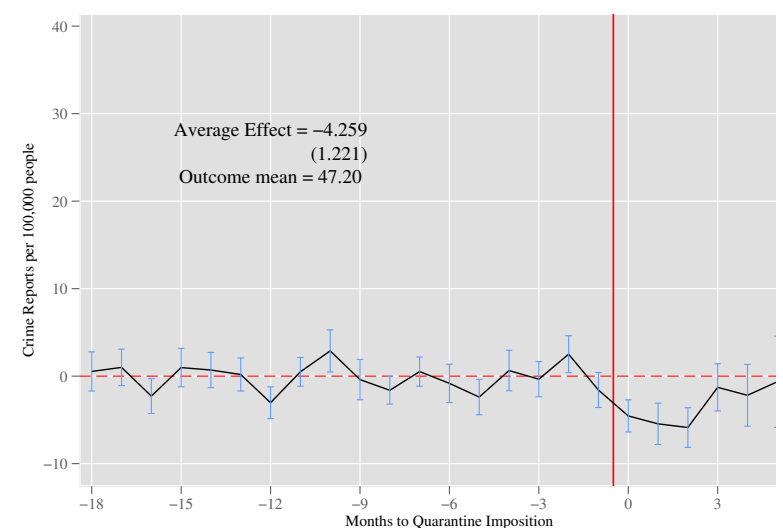

(b) Distress calls (exit)

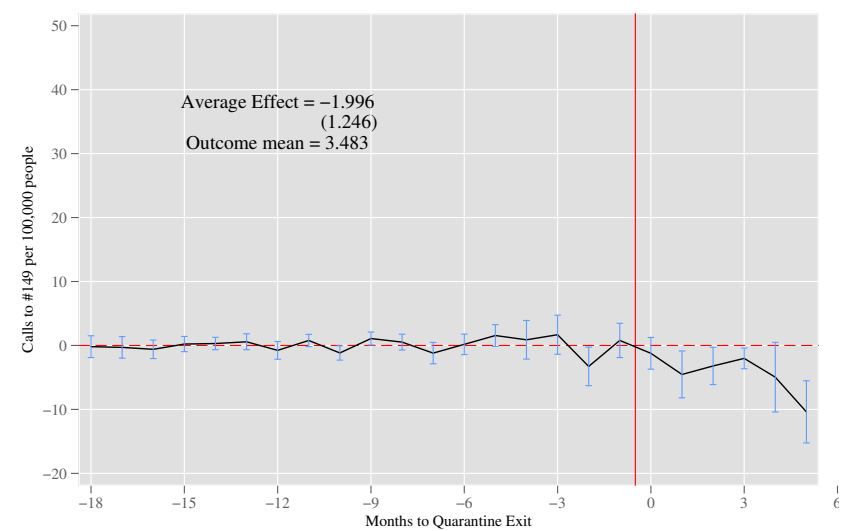

(d) Shelter usage (exit)

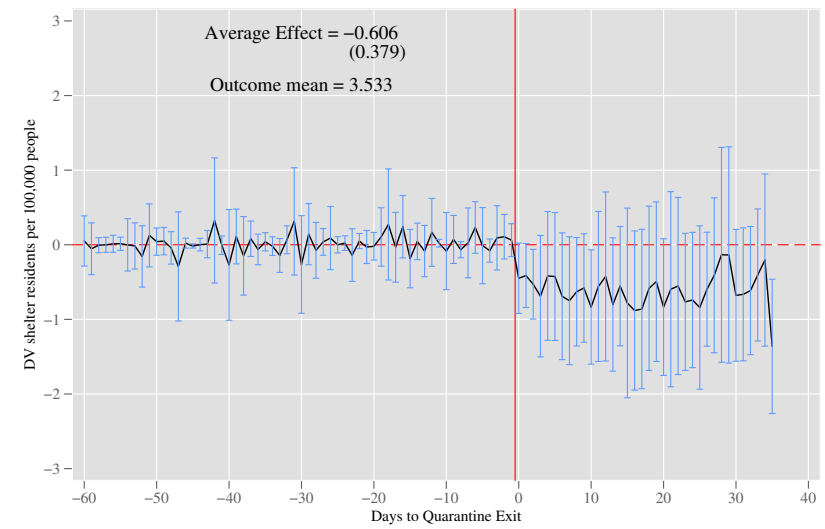

(f) Crime reporting (exit)

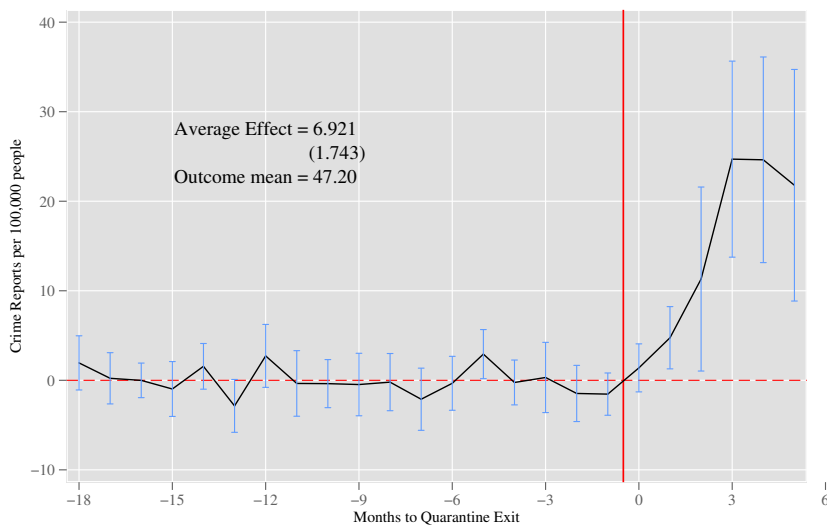

Note: refer to the note under Figure 2. Identical specifications are estimated, here without controls for COVID infection and testing rates.

Source: authors' calculations based on data presented in Appendix B. 
Figure A7: Impacts of lockdown on mechanism variables (no COVID controls)

(a) Cell phone mobility patterns (entry)

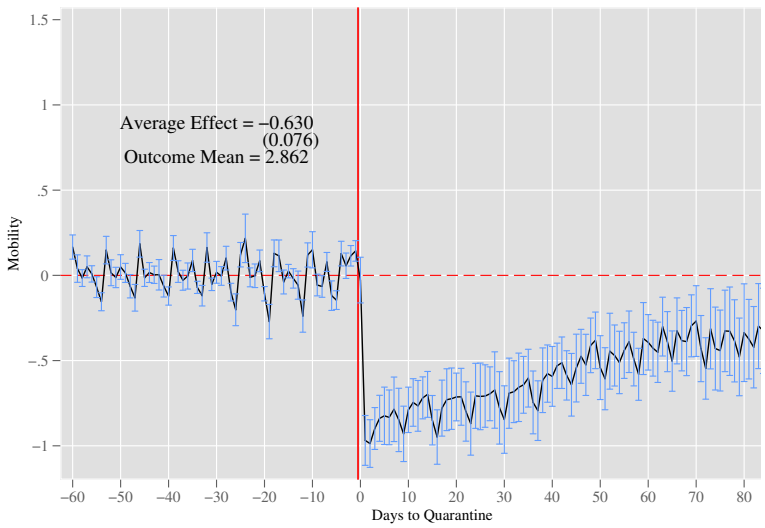

(c) Male formal employment rate (entry)

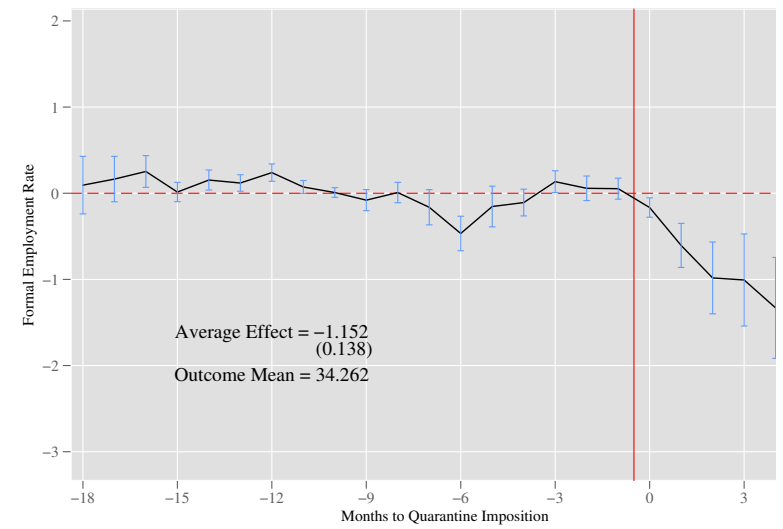

(e) Female formal employment rate (entry)

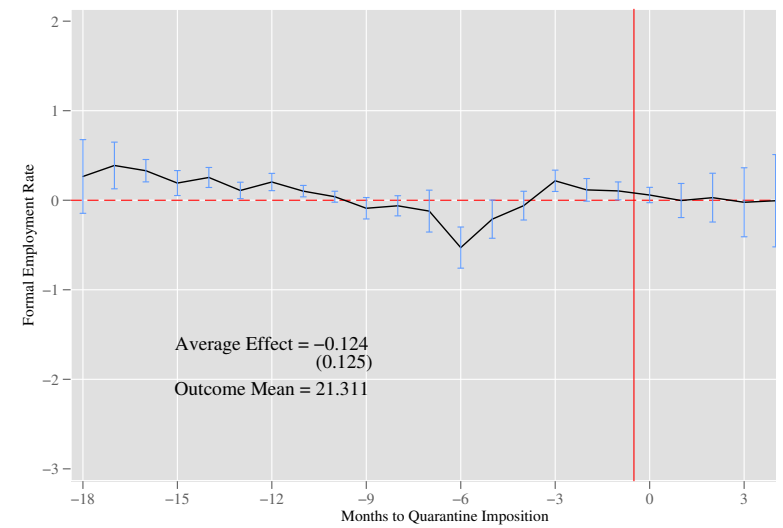

(b) Cell phone mobility patterns (exit)

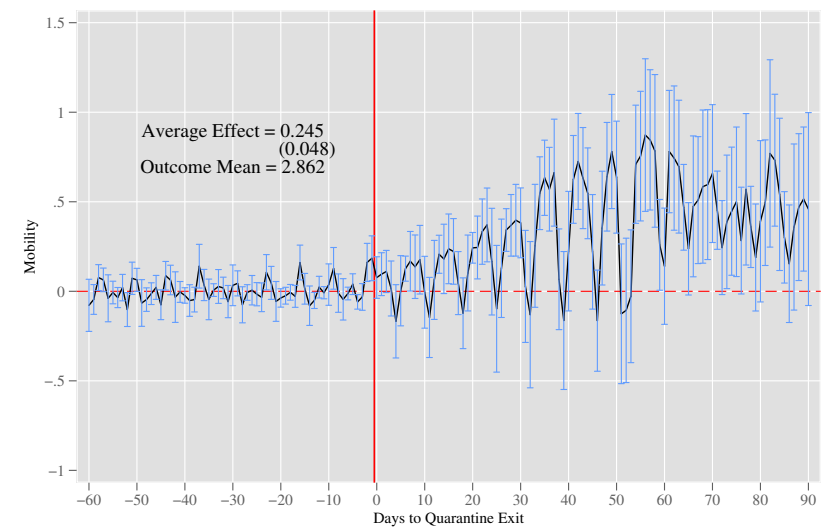

(d) Male formal employment rate (exit)

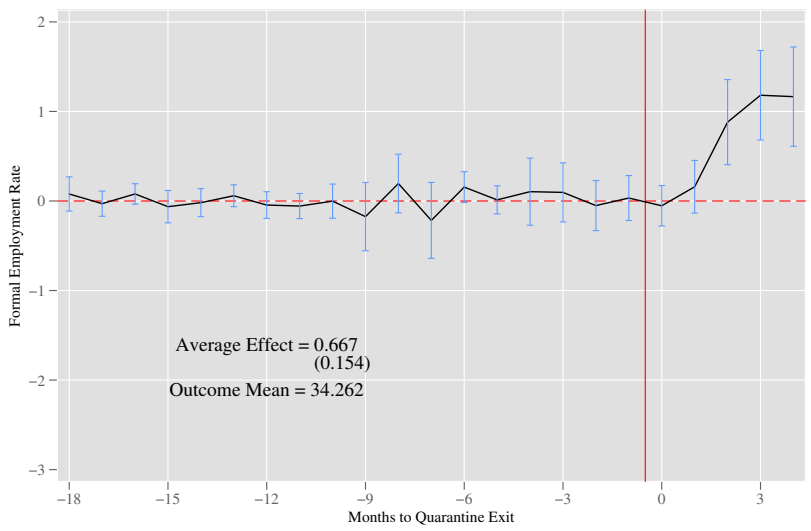

(f) Female formal employment rate (exit)

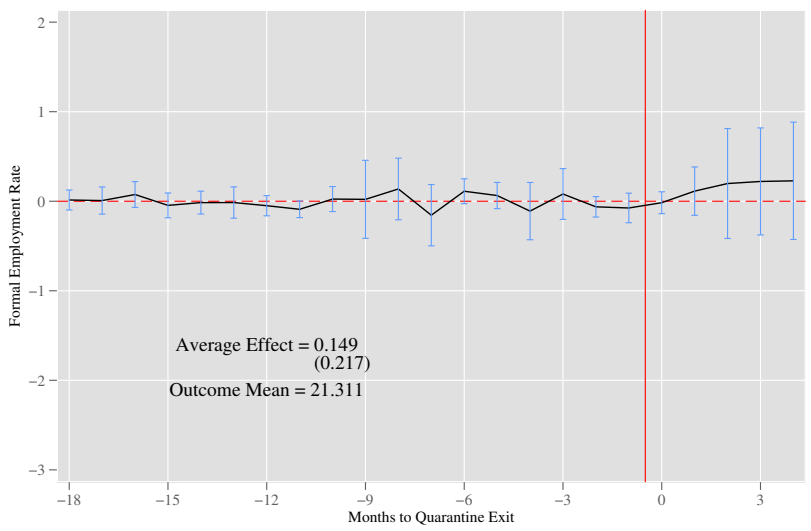

Note: refer to the note under Figure 3. Identical specifications are estimated, here without controls for COVID infection and testing rates.

Source: authors' calculations based on data presented in Appendix B. 
Figure A8: Event-study estimates of impacts of lockdown on incidence of intra-family violence

(a) Distress calls (entry)

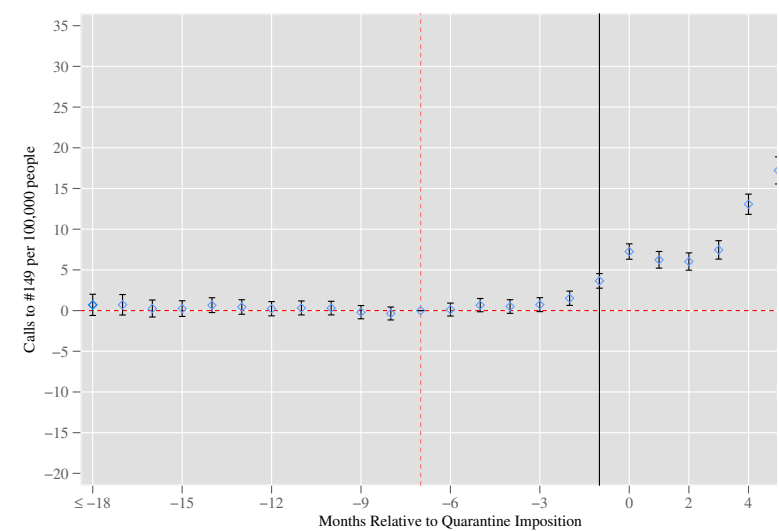

(c) Shelter usage (entry)

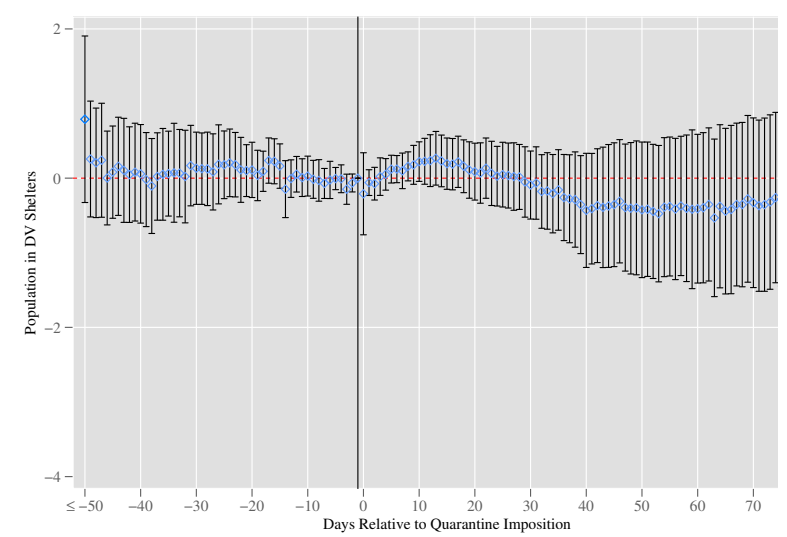

(e) Crime reporting (entry)

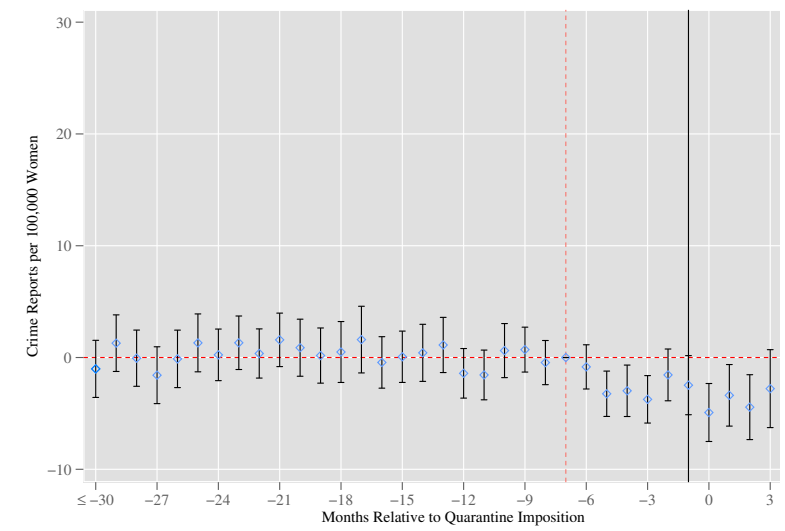

(b) Distress calls (exit)

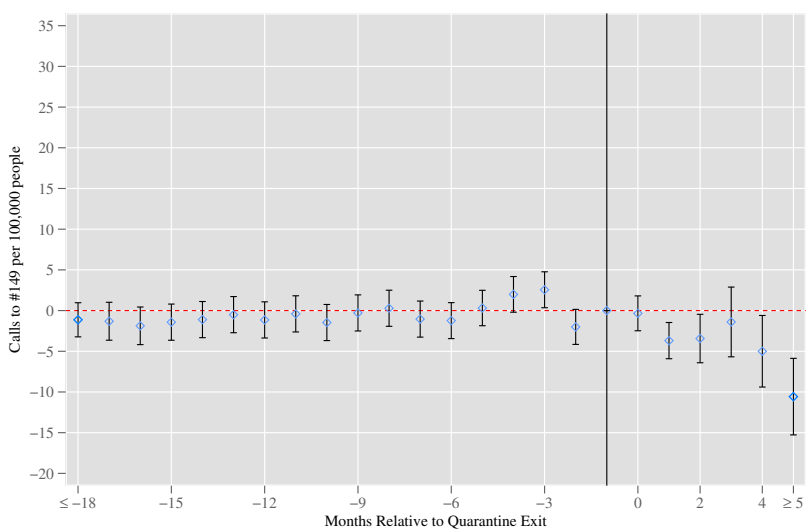

(d) Shelter usage (exit)

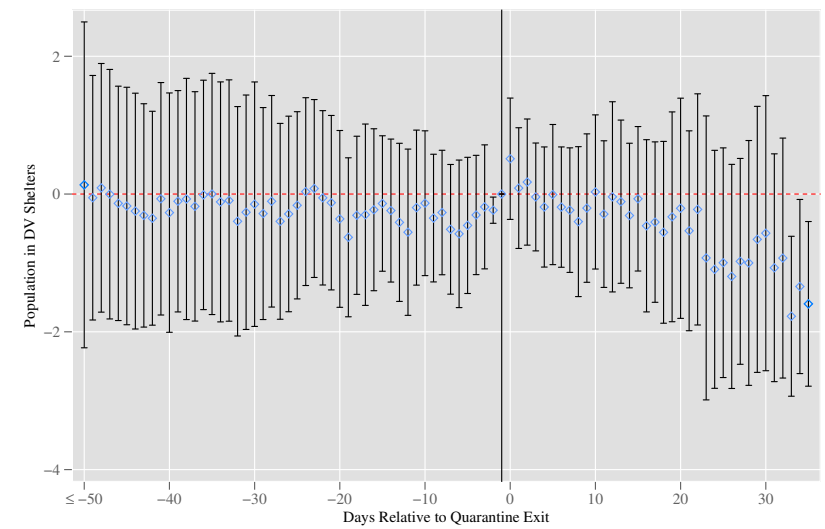

(f) Crime reporting (exit)

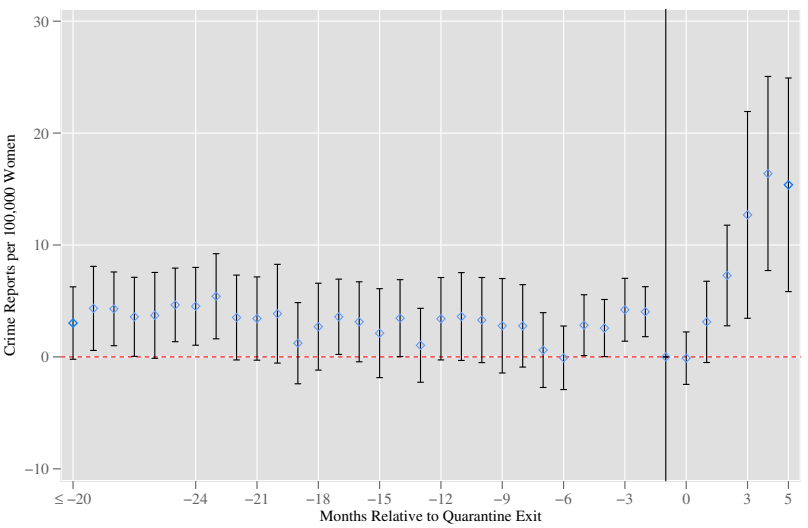

Note: panel event study coefficients and 95\% confidence intervals are displayed. The left-hand column consists of all municipalities, where the event of interest refers to the adoption of lockdown (if the municipality has ever adopted). The right-hand panel consists of all municipalities which have ever entered lockdown (and hence could theoretically exit lockdown), where the event of interest refers to the removal of lockdown. Cluster-robust standard errors are estimated by area. All other details follow those described in the note under Figure 2.

Source: authors' calculations based on data presented in Appendix B. 
Figure A9: Event-study estimates of impacts of lockdown on mechanism variables

(a) Cell phone mobility patterns (entry)

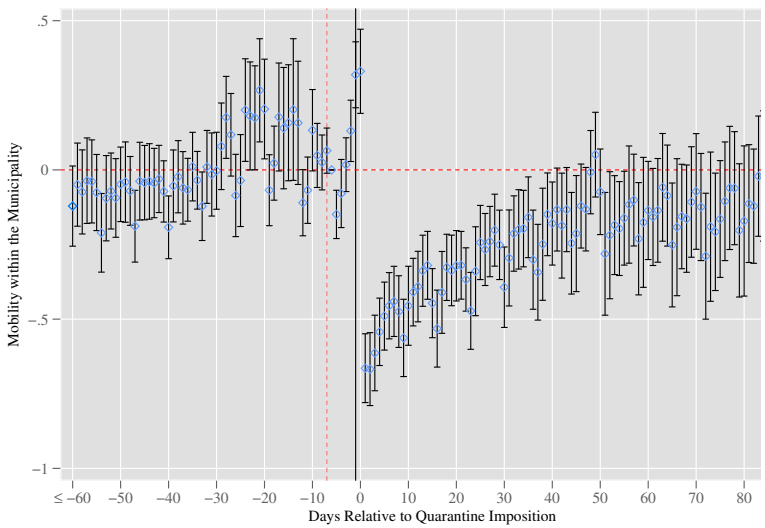

(c) Male formal employment rate (entry)

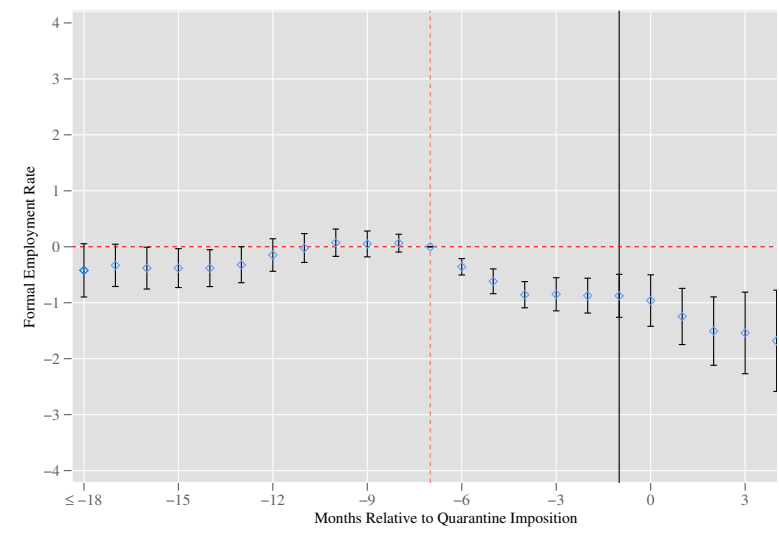

(e) Female formal employment rate (entry)

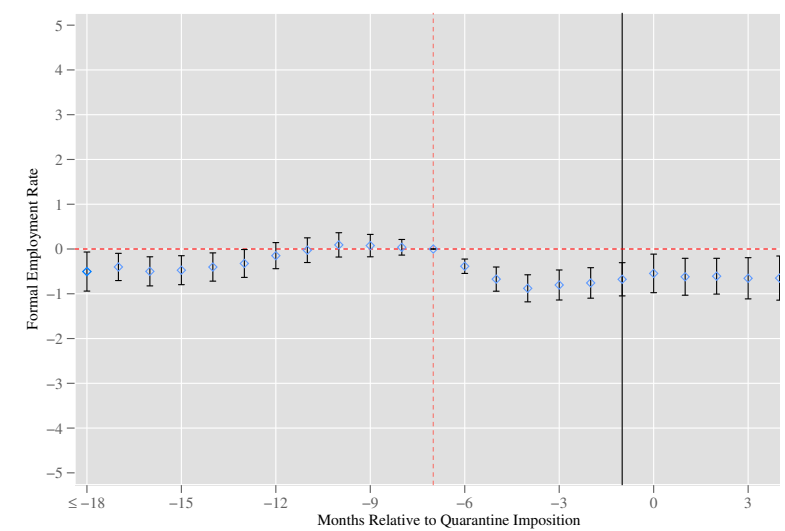

(b) Cell phone mobility patterns (exit)

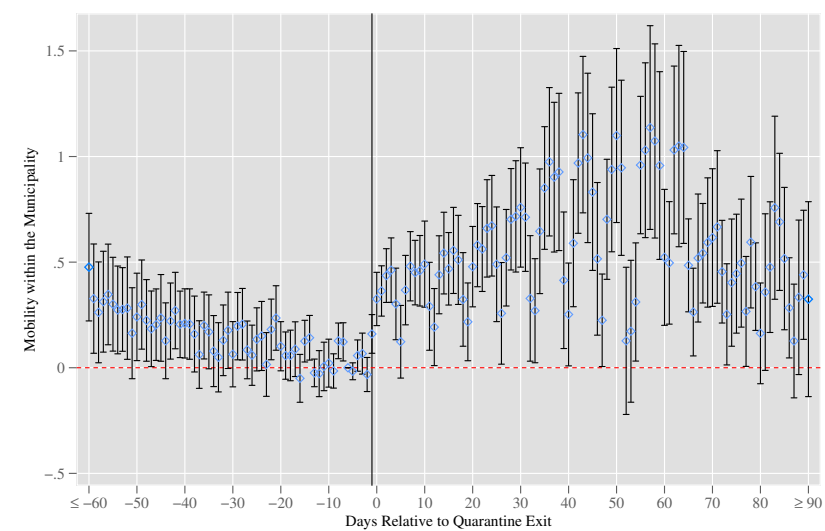

(d) Male formal employment rate (exit)

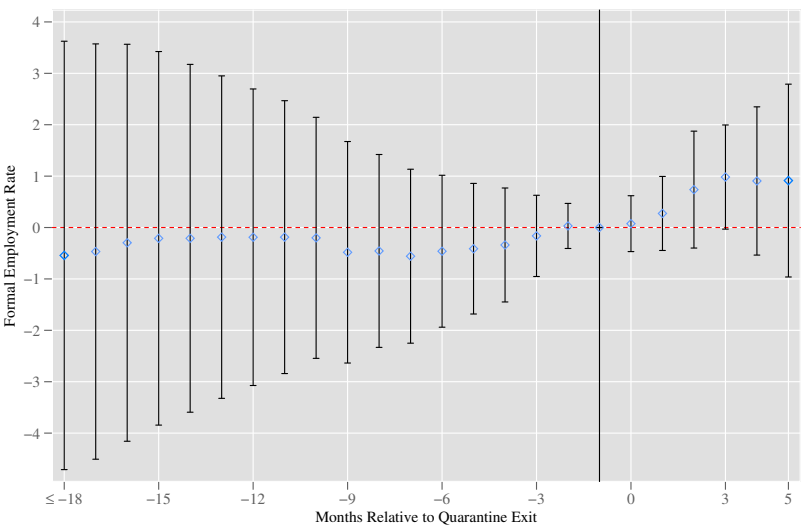

(f) Female formal employment rate (exit)

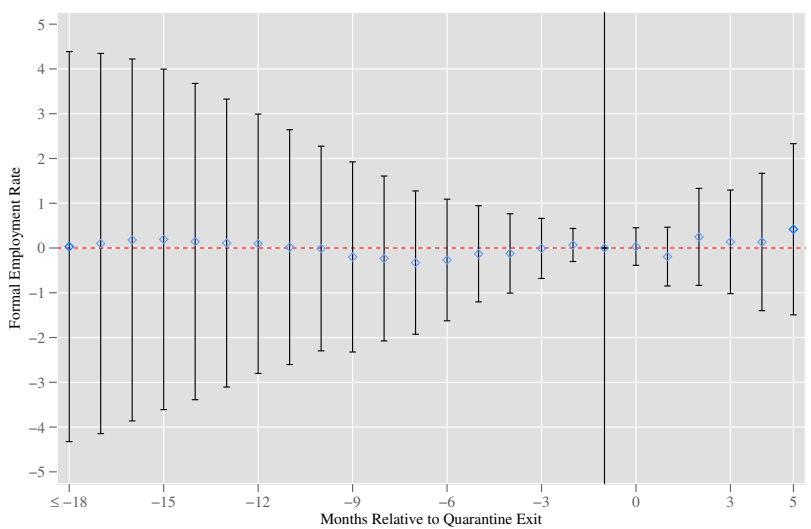

Note: refer to the note under Figure A8. Identical specifications are estimated, however examining mobility patterns based on within-municipality daily movement from cell phone data (panels (a) and (b)) and municipal-level employment rates in the formal private labour market from administrative records (panels $(c)-(f)$ ). All other estimation details follow those indicated in the note under Figure A8.

Source: authors' calculations based on data presented in Appendix B. 
Table A4: Two-way FE models_DV and mechanism measures

\begin{tabular}{|c|c|c|c|c|c|c|}
\hline & \multicolumn{3}{|c|}{ DV measures } & \multicolumn{3}{|c|}{ Mechanisms } \\
\hline & $\begin{array}{l}\text { Calls } \\
(1)\end{array}$ & $\begin{array}{l}\text { Crime } \\
(2)\end{array}$ & $\begin{array}{l}\text { Shelters } \\
\text { (3) }\end{array}$ & $\begin{array}{l}\text { Mobility } \\
\text { (4) }\end{array}$ & $\begin{array}{c}\text { Male emp } \\
\text { (5) }\end{array}$ & $\begin{array}{c}\text { Female emp } \\
\text { (6) }\end{array}$ \\
\hline \multicolumn{7}{|l|}{ Panel A: No COVID controls } \\
\hline Lockdown imposed & $\begin{array}{c}7.792^{* * *} \\
(1.062)\end{array}$ & $\begin{array}{c}-6.596^{* * *} \\
(0.960)\end{array}$ & $\begin{array}{l}0.053^{*} \\
(0.029)\end{array}$ & $\begin{array}{c}-0.269^{\star * *} \\
(0.060)\end{array}$ & $\begin{array}{c}-0.735^{* * *} \\
(0.141)\end{array}$ & $\begin{array}{l}-0.103 \\
(0.092)\end{array}$ \\
\hline Lockdown removed & $\begin{array}{c}1.746 \\
(1.202)\end{array}$ & $\begin{array}{c}0.231 \\
(1.402)\end{array}$ & $\begin{array}{l}-0.025 \\
(0.115)\end{array}$ & $\begin{array}{c}0.442^{\star \star \star} \\
(0.081)\end{array}$ & $\begin{array}{l}-0.019 \\
(0.128)\end{array}$ & $\begin{array}{l}-0.074 \\
(0.119)\end{array}$ \\
\hline Observations & 7,266 & 26,919 & 4,576 & 74,992 & 7,266 & 7,266 \\
\hline \multicolumn{7}{|l|}{ Panel B: COVID controls } \\
\hline Lockdown imposed & $\begin{array}{c}5.409^{\star \star *} \\
(0.832)\end{array}$ & $\begin{array}{c}-2.872^{\star \star *} \\
(0.923)\end{array}$ & $\begin{array}{c}0.155^{\star * *} \\
(0.034)\end{array}$ & $\begin{array}{c}-0.256^{\star \star *} \\
(0.059)\end{array}$ & $\begin{array}{c}-0.589^{\star \star *} \\
(0.148)\end{array}$ & $\begin{array}{c}0.002 \\
(0.107)\end{array}$ \\
\hline Lockdown removed & $\begin{array}{c}1.501 \\
(0.991)\end{array}$ & $\begin{array}{l}-0.216 \\
(1.308)\end{array}$ & $\begin{array}{c}0.035 \\
(0.124)\end{array}$ & $\begin{array}{c}0.429^{\star * \star} \\
(0.080)\end{array}$ & $\begin{array}{l}-0.028 \\
(0.140)\end{array}$ & $\begin{array}{l}-0.097 \\
(0.129)\end{array}$ \\
\hline Population & $\begin{array}{l}0.001^{* *} \\
(0.000)\end{array}$ & $\begin{array}{c}-0.000^{\star * *} \\
(0.000)\end{array}$ & & & $\begin{array}{l}-0.000 \\
(0.000)\end{array}$ & $\begin{array}{l}-0.000 \\
(0.000)\end{array}$ \\
\hline Diagnosed COVID cases per 1,000 people & $\begin{array}{l}0.268^{*} \\
(0.149)\end{array}$ & $\begin{array}{l}-0.175 \\
(0.140)\end{array}$ & $\begin{array}{c}-0.566^{\star * *} \\
(0.164)\end{array}$ & $\begin{array}{c}0.024 \\
(0.040)\end{array}$ & $\begin{array}{c}-0.070^{\star * *} \\
(0.019)\end{array}$ & $\begin{array}{c}0.011 \\
(0.015)\end{array}$ \\
\hline PCR tests per 1,000 people & $\begin{array}{c}-0.064^{\star *} \\
(0.029)\end{array}$ & $\begin{array}{l}-0.025 \\
(0.031)\end{array}$ & $\begin{array}{c}-0.166^{\star * *} \\
(0.042)\end{array}$ & $\begin{array}{c}-0.022^{* *} \\
(0.009)\end{array}$ & $\begin{array}{c}0.025^{* * *} \\
(0.004)\end{array}$ & $\begin{array}{c}0.004 \\
(0.003)\end{array}$ \\
\hline Rate of positive PCR tests & $\begin{array}{c}0.077 \\
(0.051)\end{array}$ & $\begin{array}{c}-0.161^{* * *} \\
(0.049)\end{array}$ & $\begin{array}{c}0.002 \\
(0.002)\end{array}$ & $\begin{array}{c}-0.001^{* *} \\
(0.000)\end{array}$ & $\begin{array}{c}0.000 \\
(0.008)\end{array}$ & $\begin{array}{c}-0.011^{\star *} \\
(0.006)\end{array}$ \\
\hline Observations & 7,266 & 26,919 & 4,528 & 74,992 & 7,266 & 7,266 \\
\hline Mean of dep. var. (baseline) & 3.482 & 47.20 & 3.533 & 2.862 & 34.26 & 21.31 \\
\hline
\end{tabular}

Note: each column displays a two-way fixed-effect regression of the impact of lockdown on domestic violence measures (columns 1-3) or mechanism variables (columns 4-6). In columns 1-3, all measures are cast per 100,000 population. Column 4 refers to average trips within municipality per day, columns 5-.6 are cast per 100,000 working-age population. 'Lockdown imposed' is a binary variable taking the value of 1 only when municipalities are under lockdown, and 0 pre or post-lockdown. 'Lockdown removed' switches to 1 post-lockdown in areas where lockdown has been imposed and then removed. Population is not included in columns 3-4 given that these are day by municipality measures for 2020 only. Fixed effects for area and time are consistently included, and standard areas are clustered by geographic unit. ${ }^{* * *},{ }^{* *}$, and ${ }^{*}$ indicate statistical significance at the $1 \%, 5 \%$, and $10 \%$, respectively.

Source: authors' calculations based on data presented in Appendix B. 
Figure A10: Decomposing the two-way fixed-effect estimate-municipal-level lockdown entry

(a) Distress calls

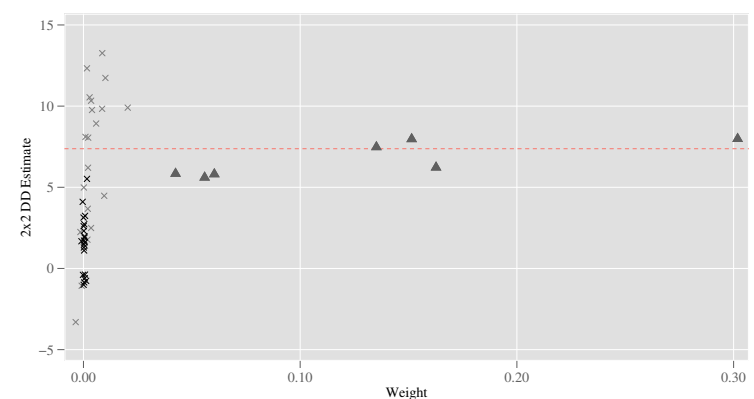

$\times$ Earlier Group Treatment vs. Later Group Control

$\times$ Later Group Treatment vs. Ear (b) Crime reporting

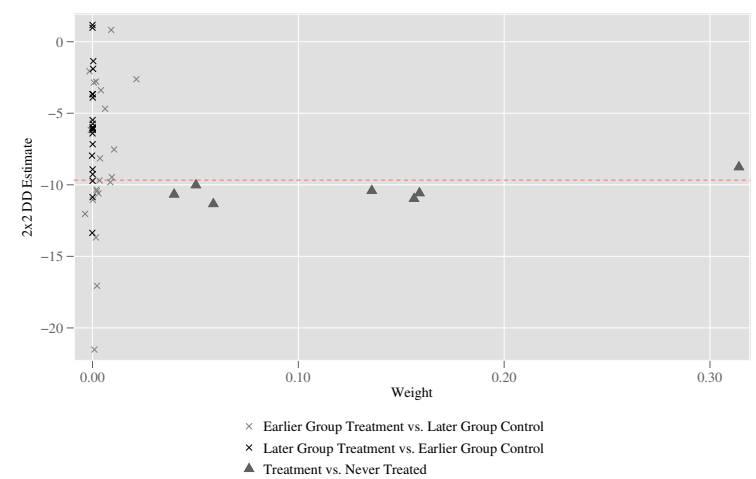

Note: decomoposition of the two-way fixed-effect estimator follows Goodman-Bacon (2021), plotting each group $\times$ time estimate as well as its weight in two-way fixed-effect models. Results are presented for municipal by month records, in which each of the three Goodman-Bacon (2021) groups exist (treated vs never treated, early versus late adoption, late versus early adoption).

The group-specific estimates are presented as points on the plot, while the aggregate two-way FE estimate is presented as the dashed horizontal line.

Source: authors' calculations based on data presented in Appendix B. 
Figure A11: Honest DID bounds estimates of impacts of lockdown on incidence of intra-family violence

(a) Distress calls (entry)

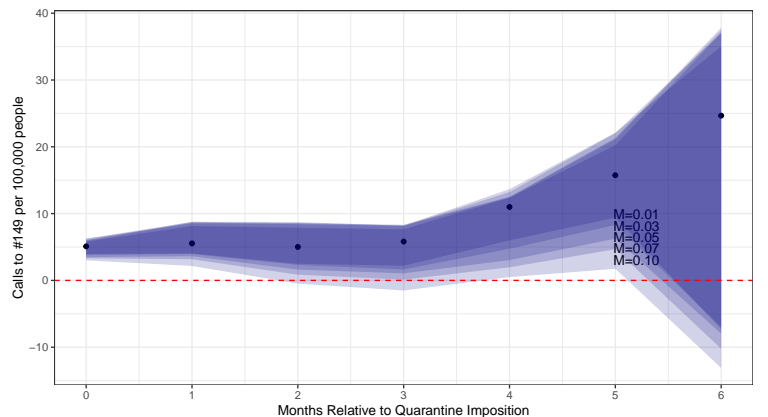

(c) Shelter usage (entry)

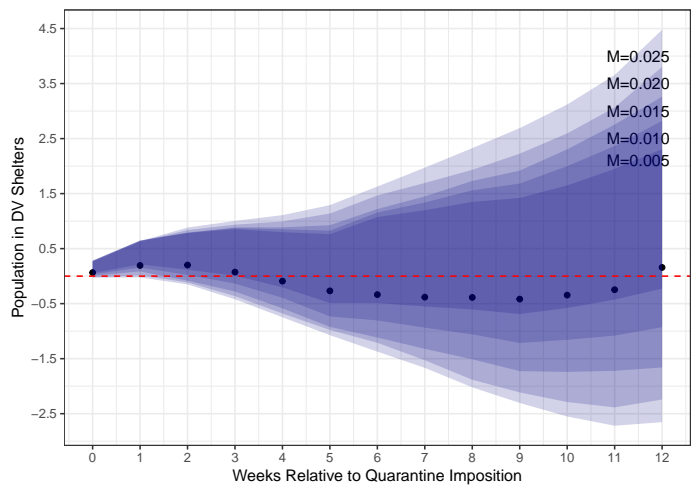

(e) Crime reporting (entry)

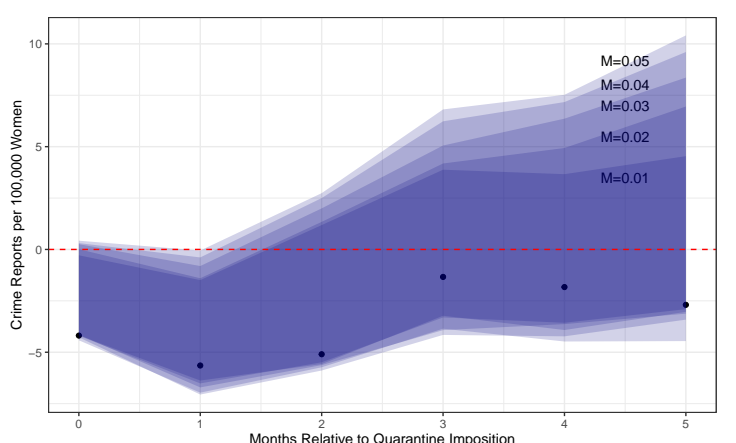

(b) Distress calls (exit)

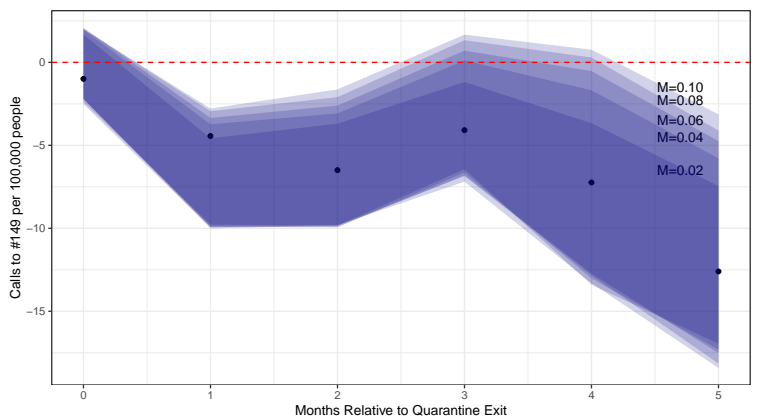

(d) Shelter usage (exit)

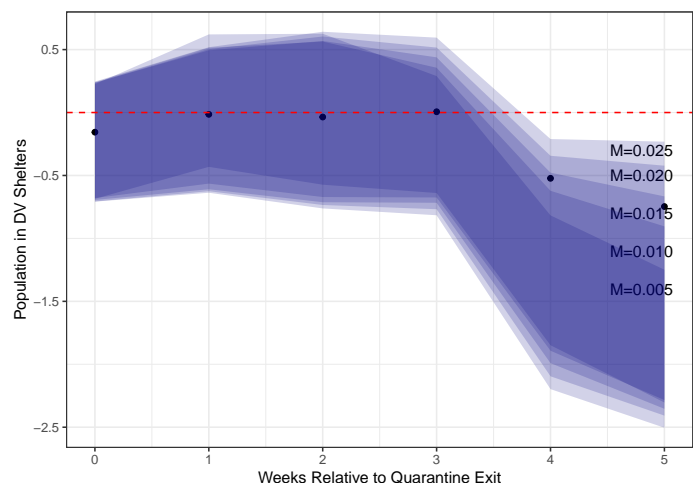

(f) Crime reporting (exit)

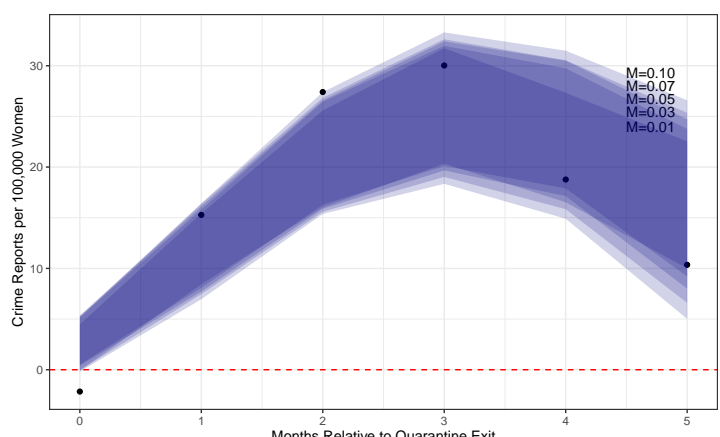

Note: figures replicate post-event lags from panel event study models, however now rather than assuming parallel counterfactual trends between lockdown and non-lockdown municipalities, project any prevailing trends forward, resulting in partially identified 'Honest DiD' bounds. Additionally, these trends are allowed to vary by as much as $M$ between each period, where varying values of $M$ are plotted as alternative $95 \%$ confidence intervals. In the case of shelter usage only, weekly, rather than daily estimates are plotted, given computational demands on bounds when many lags are included. Point estimates from event studies are included as solid circles for reference.

Source: authors' calculations based on data presented in Appendix B. 
Figure A12: Honest DID bounds estimates of impacts of lockdown on mechanism variables

(a) Cell phone mobility patterns (entry)

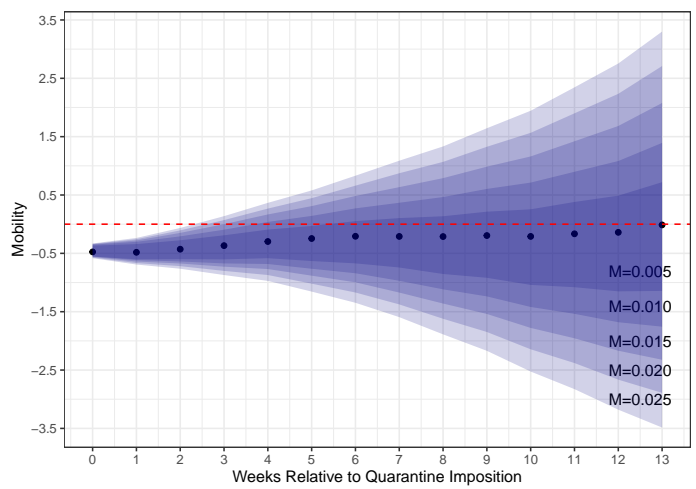

(c) Male formal employment rate (entry)

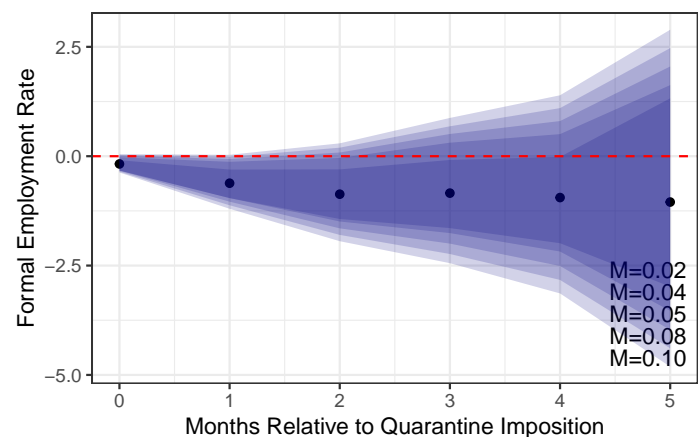

(e) Female formal employment rate (entry)

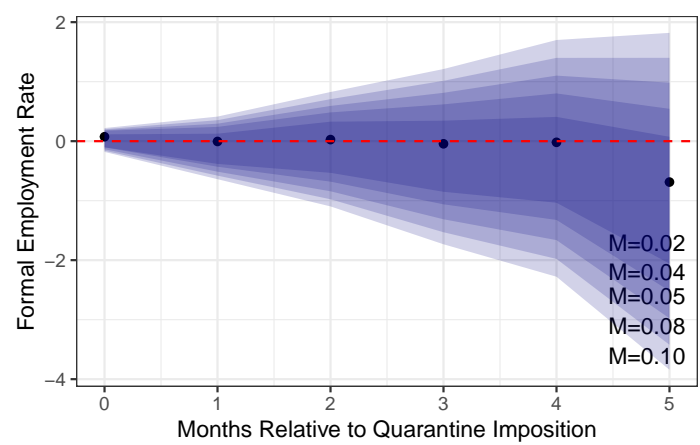

(b) Cell phone mobility patterns (exit)

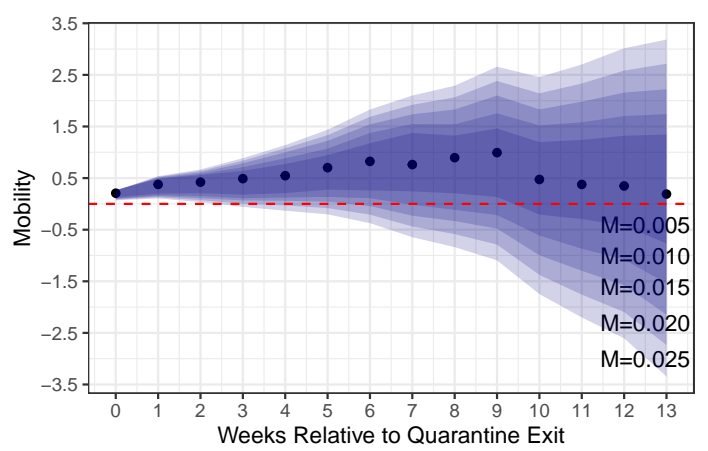

(d) Male formal employment rate (exit)

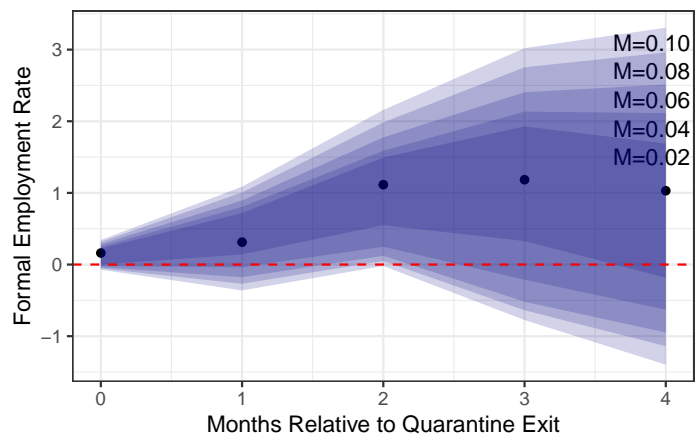

(f) Female formal employment rate (exit)

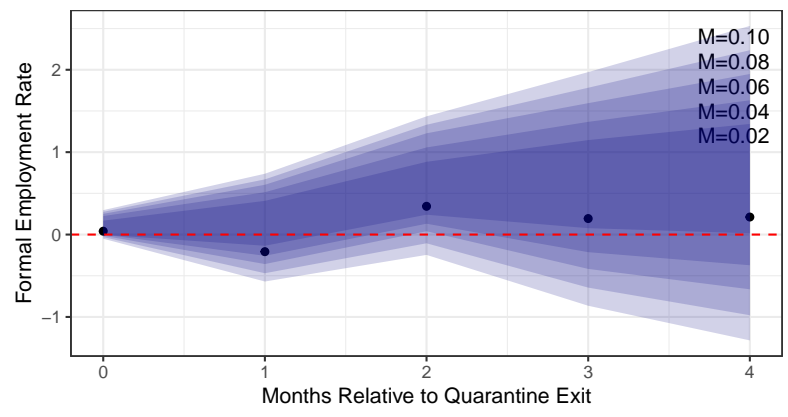

Note: refer to the note under Figure A11. Identical specifications are estimated, however examining mobility patterns based on within-municipality movement from cell phone data (panels (a) and (b)) and municipal-level employment rates in the formal private labour market from administrative records (panels (c)-(f)). In the case of mobility measures only, weekly, rather than daily estimates are plotted, given computational demands on bounds when many lags are included. All other estimation details follow those indicated in the note under Figure A11.

Source: authors' calculations based on data presented in Appendix B. 
Table A5: Stimulus Payment Amounts and Dates

\begin{tabular}{llc}
\hline Payment & Date first deposit & Average amount \\
\hline Payment 1 & May 25, 2020 & 154,378 CLP \\
Payment 2 & June 25, 2020 & 197,455 CLP \\
Payment 3 & July 28, 2020 & 194,017 CLP \\
Payment 4 & August 27, 2020 & 193,201 CLP \\
\hline
\end{tabular}

Source: authors' calculations based on data presented in Appendix B.

Figure A13: IFE stimulus payments

(a) Payments over time

(b) Proportion of recipients per municipality
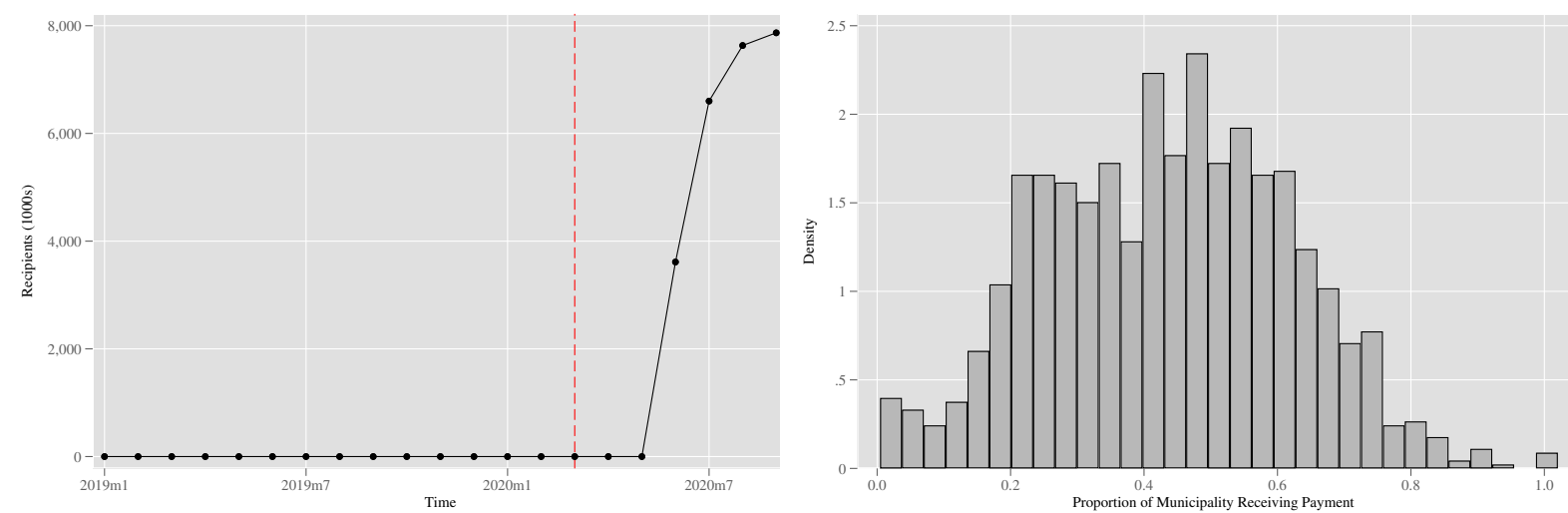

Note: panel (a) plots the temporal expansion of the number of IFE recipients nationwide, based on administrative records provided by the Ministry of Social Development of Chile (Undersecretary for Social Evaluation). Panel (b) plots the average proportion of each municipality's residents receiving an IFE payment, calculated in the period following the introduction of the payment.

Source: authors' calculations based on data presented in Appendix B. 


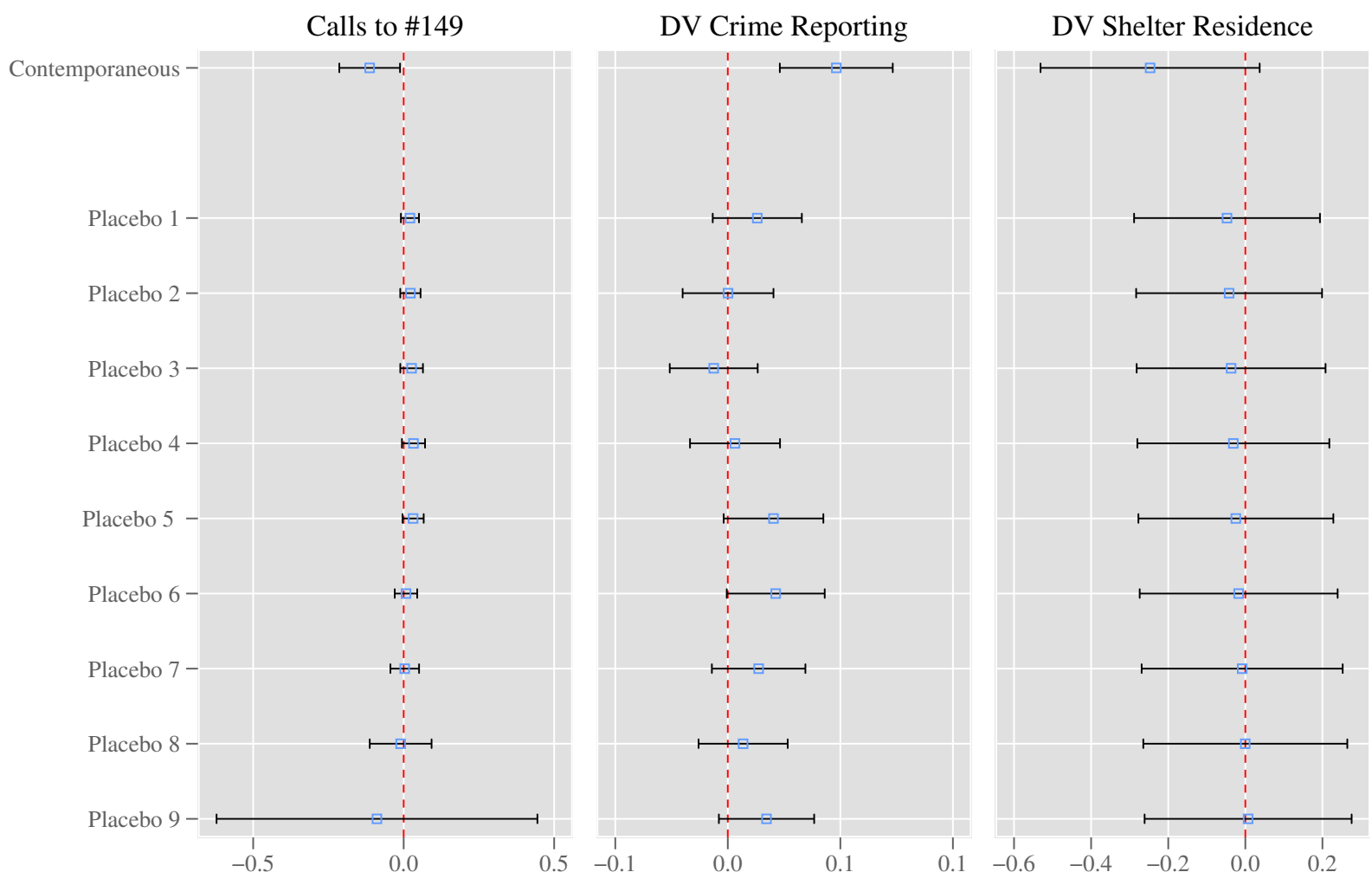

Estimated Impact of IFE (Stimulus) Payment

Note: placebo tests consist of estimating two-way FE models with rates of IFE payments as the independent variable of interest on rates of domestic violence. In the case of 'Contemporaneous' models, this consists simply of a regression of rates of DV in time $t$ on IFE (family emergency income payments) at time $t$, whereas placebos regress lagged rates of DV at time $t-k$ on IFE at time $t$. In the case of Calls and Crime, alternative placebos use lags $k \in\{10,11, \ldots, 18\}$, such that in all cases DV outcomes are considered in months of 2019 or prior. In the case of shelters where daily data is used (starting from January 2020), lags $k \in\{60,61, \ldots, 68\}$ are considered.

Source: authors' calculations based on data presented in Appendix B. 
Table A6: Stimulus payments, lockdown, and domestic violence (alternative specifications)

\begin{tabular}{|c|c|c|c|c|c|c|}
\hline & \multicolumn{2}{|c|}{ Calls to 149} & \multicolumn{2}{|c|}{ Crime reporting } & \multicolumn{2}{|c|}{ Shelter residence } \\
\hline & $(1)$ & $(2)$ & (3) & (4) & $(5)$ & $(6)$ \\
\hline \multicolumn{7}{|c|}{ Panel A: Unstandardized } \\
\hline Lockdown & $\begin{array}{c}5.239^{* * *} \\
(0.833)\end{array}$ & $\begin{array}{c}6.786^{* * *} \\
(1.139)\end{array}$ & $\begin{array}{c}-2.198^{* *} \\
(0.885)\end{array}$ & $\begin{array}{c}-1.332 \\
(1.263)\end{array}$ & $\begin{array}{c}0.157 \\
(0.200)\end{array}$ & $\begin{array}{c}0.188 \\
(0.208)\end{array}$ \\
\hline IFE & $\begin{array}{l}-1.944 \\
(2.424)\end{array}$ & $\begin{array}{l}-1.421 \\
(2.357)\end{array}$ & $\begin{array}{c}12.65^{\star * \star} \\
(3.625)\end{array}$ & $\begin{array}{c}13.15^{* * \star} \\
(3.413)\end{array}$ & $\begin{array}{l}-3.033^{*} \\
(1.664)\end{array}$ & $\begin{array}{l}-3.023^{*} \\
(1.680)\end{array}$ \\
\hline Lockdown $\times$ IFE & & $\begin{array}{c}-6.689^{\star *} \\
(3.241)\end{array}$ & & $\begin{array}{l}-3.777 \\
(4.100)\end{array}$ & & $\begin{array}{l}-0.117 \\
(0.402)\end{array}$ \\
\hline $\begin{array}{l}\text { IFE + } \\
\text { Lockdown } \times \text { IFE }\end{array}$ & & $\begin{array}{l}-8.110^{\star} \\
(4.824)\end{array}$ & & $\begin{array}{c}9.375 \\
(5.860)\end{array}$ & & $\begin{array}{l}-3.140^{*} \\
(1.670)\end{array}$ \\
\hline Observations & 7,245 & 7,245 & 26,841 & 26,841 & 4,128 & 4,128 \\
\hline R-squared & 0.784 & 0.786 & 0.560 & 0.560 & 0.856 & 0.856 \\
\hline \multicolumn{7}{|c|}{ Panel B: No COVID-19 controls } \\
\hline Lockdown & $\begin{array}{l}0.160^{* * *} \\
(0.0202)\end{array}$ & $\begin{array}{l}0.206^{\star * *} \\
(0.0353)\end{array}$ & $\begin{array}{c}-0.0218^{\star \star \star} \\
(0.00342)\end{array}$ & $\begin{array}{l}-0.0231^{\star \star *} \\
(0.00507)\end{array}$ & $\begin{array}{c}0.0144 \\
(0.0330)\end{array}$ & $\begin{array}{c}0.0227 \\
(0.0391)\end{array}$ \\
\hline IFE & $\begin{array}{c}-0.108 \\
(0.0777)\end{array}$ & $\begin{array}{l}-0.0914 \\
(0.0710)\end{array}$ & $\begin{array}{c}0.0456^{* * *} \\
(0.0124)\end{array}$ & $\begin{array}{c}0.0448^{* \star *} \\
(0.0117)\end{array}$ & $\begin{array}{l}-0.260^{*} \\
(0.145)\end{array}$ & $\begin{array}{c}-0.259^{*} \\
(0.147)\end{array}$ \\
\hline Lockdown $\times$ IFE & & $\begin{array}{c}-0.0728^{\star *} \\
(0.0344)\end{array}$ & & $\begin{array}{c}0.00199 \\
(0.00526)\end{array}$ & & $\begin{array}{l}-0.0132 \\
(0.0371)\end{array}$ \\
\hline $\begin{array}{l}\text { IFE + } \\
\text { Lockdown } \times \text { IFE }\end{array}$ & & $\begin{array}{l}-0.164^{*} \\
(0.099)\end{array}$ & & $\begin{array}{c}0.046^{* * *} \\
(0.014)\end{array}$ & & $\begin{array}{l}-0.272^{*} \\
(0.146)\end{array}$ \\
\hline Observations & 7,262 & 7,262 & 26,915 & 26,915 & 4,176 & 4,176 \\
\hline R-squared & 0.770 & 0.773 & 0.558 & 0.558 & 0.853 & 0.853 \\
\hline
\end{tabular}

Note: refer to the note under Table 2. Identical models are estimated, however here using all variables in levels rather than standardized units (panel A), and not including controls for time-varying measures of COVID-19 intensity (panel B). All other details follow those described in Table $2 .{ }^{* * *} p<0.01,{ }^{* \star} p<0.05,{ }^{*} p<0.1$.

Source: authors' calculations based on data presented in Appendix B. 


\section{B Data Appendix}

Table B1: Data definitions and sources

\begin{tabular}{|c|c|c|c|c|c|}
\hline Variable & Description & Frequency & Unit of analysis & $\begin{array}{l}\text { Period cov- } \\
\text { ered }\end{array}$ & Source \\
\hline $\begin{array}{l}\text { Distress calls } \\
\text { to the police } \\
\text { DV hotline }\end{array}$ & $\begin{array}{l}\text { Number of calls received by the domestic vi- } \\
\text { olence police line } \# 149 \text { per } 100,000 \text { inhabi- } \\
\text { tants. The calls are classified as owing to } \\
\text { complaints related to physical violence, psy- } \\
\text { chological violence, and economic violence. }\end{array}$ & Monthly & Municipality & $\begin{array}{l}\text { Jan } 2019- \\
\text { Sept } 2020\end{array}$ & Carabineros de Chile \\
\hline $\begin{array}{ll}\text { Crimes re- } \\
\text { ported for } \\
\text { DV }\end{array}$ & $\begin{array}{l}\text { Domestic violence crimes known to the po- } \\
\text { lice. They include formal complaints made to } \\
\text { the police, as well as in flagrant offences }\end{array}$ & Monthly & Municipality & $\begin{array}{l}\text { Jan } 2015- \\
\text { Sept } 2020\end{array}$ & $\begin{array}{l}\text { Ministry of Interior, Undersec- } \\
\text { retary of Crime Prevention }\end{array}$ \\
\hline $\begin{array}{l}\text { Residents in } \\
\text { DV shelters }\end{array}$ & $\begin{array}{l}\text { Number of residents in government-run do- } \\
\text { mestic violence shelters measured as the } \\
\text { number of women who slept in a shelter the } \\
\text { night before per } 100,000 \text { inhabitants }\end{array}$ & Daily & Region & $\begin{array}{l}\text { Jan } 1,2020- \\
\text { Nov } 6,2020\end{array}$ & $\begin{array}{l}\text { Ministry of Women and Gen- } \\
\text { der Equality }\end{array}$ \\
\hline $\begin{array}{l}\text { Spots in DV } \\
\text { shelters }\end{array}$ & $\begin{array}{l}\text { Number of official spots available in } \\
\text { government-run domestic violence shel- } \\
\text { ters }\end{array}$ & Daily & Region & $\begin{array}{l}\text { Jan } 1,2020- \\
\text { Sept } 30,2020\end{array}$ & $\begin{array}{l}\text { Ministry of Women and Gen- } \\
\text { der Equality }\end{array}$ \\
\hline $\begin{array}{l}\text { Lockdown } \\
\text { entry }\end{array}$ & $\begin{array}{l}\text { Dummy indicating a municipality is under } \\
\text { lockdown }\end{array}$ & Daily & Municipality & $\begin{array}{l}\text { Mar } 14,2020- \\
\text { Sept } 30,2020\end{array}$ & $\begin{array}{l}\text { Ministry of Health, hand- } \\
\text { compiled by project RA }\end{array}$ \\
\hline $\begin{array}{l}\text { Lockdown } \\
\text { exit }\end{array}$ & $\begin{array}{l}\text { Dummy indicating a municipality has exited } \\
\text { lockdown }\end{array}$ & Daily & Municipality & $\begin{array}{l}\text { Mar } 14,2020- \\
\text { Sept } 30,2020\end{array}$ & $\begin{array}{l}\text { Ministry of Health, hand- } \\
\text { compiled by project RA }\end{array}$ \\
\hline $\begin{array}{l}\text { COVID-19 } \\
\text { testing rate }\end{array}$ & $\begin{array}{l}\text { Number of COVID-19 PCRs over 1,000 in- } \\
\text { habitants }\end{array}$ & Daily & Municipality & $\begin{array}{l}\text { Mar } 8,2020- \\
\text { Sept } 30,2020\end{array}$ & Ministry of Science \\
\hline $\begin{array}{l}\text { COVID-19 in- } \\
\text { fection rate }\end{array}$ & $\begin{array}{l}\text { Number of confirmed COVID-19 cases over } \\
1,000 \text { inhabitants ( } 7 \text {-day average) }\end{array}$ & Daily & Municipality & $\begin{array}{l}\text { Mar } 8,2020- \\
\text { Sept } 30,2020\end{array}$ & Ministry of Science \\
\hline $\begin{array}{l}\text { COVID-19 } \\
\text { positivity rate }\end{array}$ & $\begin{array}{l}\text { Number of confirmed COVID-19 cases over } \\
\text { PCRs (7-day average) }\end{array}$ & Daily & Municipality & $\begin{array}{l}\text { Mar } 8,2020- \\
\text { Sept } 30,2020\end{array}$ & Ministry of Science \\
\hline Mobility & $\begin{array}{l}\text { Number of trips within and between munici- } \\
\text { palities measured as changes in cell phone } \\
\text { connection towers }\end{array}$ & Daily & Municipality & $\begin{array}{l}\text { Feb 26, 2020- } \\
\text { Sept 30, } 2020\end{array}$ & $\begin{array}{l}\text { Cell phone metadata (Bravo } \\
\text { and Ferres 2020) }\end{array}$ \\
\hline Employment & $\begin{array}{l}\text { Number of employed individuals in the formal } \\
\text { private sector over working age population }\end{array}$ & Monthly & Municipality & $\begin{array}{l}\text { Jan } 2019- \\
\text { Sept } 2020\end{array}$ & $\begin{array}{l}\text { Unemployment Insurance } \\
\text { data managed by the Pen- } \\
\text { sions Superintendence }\end{array}$ \\
\hline Mean wages & $\begin{array}{l}\text { Mean wage among employed individuals in } \\
\text { the formal private sector }\end{array}$ & Monthly & Municipality & $\begin{array}{l}\text { Jan } 2019- \\
\text { Sept } 2020\end{array}$ & $\begin{array}{l}\text { Unemployment Insurance } \\
\text { data managed by the Pen- } \\
\text { sions Superintendence }\end{array}$ \\
\hline $\begin{array}{l}\text { Median } \\
\text { wages }\end{array}$ & $\begin{array}{l}\text { Median wage among employed individuals in } \\
\text { the formal private sector }\end{array}$ & Monthly & Municipality & $\begin{array}{l}\text { Jan } 2019- \\
\text { Sept } 2020\end{array}$ & $\begin{array}{l}\text { Unemployment Insurance } \\
\text { data managed by the Pen- } \\
\text { sions Superintendence }\end{array}$ \\
\hline $\begin{array}{l}\text { Jobs fur- } \\
\text { loughed }\end{array}$ & $\begin{array}{l}\text { Number of jobs furloughed under the employ- } \\
\text { ment protection law over } 100,000 \text { pre-COVID } \\
\text { jobs }\end{array}$ & Monthly & Municipality & $\begin{array}{l}\text { April } 2020- \\
\text { Sept } 2020\end{array}$ & Pensions Superintendence \\
\hline $\begin{array}{l}\text { Jobs sectoral } \\
\text { shares }\end{array}$ & $\begin{array}{l}\text { Share of private sector workers under con- } \\
\text { tract working in different economic sectors }\end{array}$ & Monthly & Municipality & & $\begin{array}{l}12 \% \text { random sample of af- } \\
\text { filiated workers to the Un- } \\
\text { employment Insurance, data } \\
\text { managed by the Pensions } \\
\text { Superintendence }\end{array}$ \\
\hline $\begin{array}{l}\text { Stimulus pay- } \\
\text { ment }\end{array}$ & $\begin{array}{l}\text { Number of people receiving the IFE benefit } \\
\text { over population }\end{array}$ & & Municipality & $\begin{array}{l}\text { May } 2020- \\
\text { Sept } 2020\end{array}$ & $\begin{array}{l}\text { Ministry of Social Develop- } \\
\text { ment and Family }\end{array}$ \\
\hline
\end{tabular}


We use three measures of domestic violence which capture incidence and reporting: calls received by the police domestic violence hotline, criminal cases of domestic violence, and use of shelters for victims of domestic violence.

Figure B1 plots the national trend for calls received by the police to the \#149 domestic violence hotline. The figure shows a sharp increase of around 300 per cent following the first outbreak of COVID-19, with the first lockdown measures soon after. Prior to March 2020 around 1,000-1,500 calls per month were received, with this quantity increasing to anywhere between around 2,000-5,000 calls per month after March 2020.

Figure B2 shows the national trend for formal criminal cases of domestic violence filed with the police. In this case, we observe daily data from 1 January 2018 to 31 May 2020. We see that by mid-March 2020 , the rate of DV criminal complaints differs from that of previous years, in particular, being lower than the rate observed in 2018 and 2019.

In the case of shelters, we observe data for each one of the publicly run women's shelters in the country, recording their number of residents and available spots on each day between 1 January 2020 and 6 November 2020. ${ }^{18}$ Not all municipalities have a shelter. In emergency situations, individuals are placed in a shelter in their region (which contains their municipality). The daily averages for rate of residence in DV shelters and total capacity for the period under study are summarized in Table B2, and national trends are plotted in Figures B3 and B4, respectively. Figure B5 shows correlations between the three main outcome variables.

We additionally have information from late February 2020 (before cases of COVID-19 were detected in Chile) recording movement within and between municipalities based on cellphone records. Baseline mobility within municipalities is approximately three trips per day (see Table B2), with trips measured as the average number of changes between cell phone connection towers from cell phone metadata. ${ }^{19}$ Figure B6 displays mobility rates, showing a significant decrease in mobility since the start of the pandemic that is more pronounced in municipalities subject to lockdown. Google's mobility index is plotted in Figure B7, showing a striking shift of activity away from workplaces and grocery stores towards residences. We do not use these data in the analysis as they provide regional aggregates, while the cell phone data provide the more fine-grained municipal measures.

We have labour market data containing information on individual monthly work histories, along with sector of work, and whether workers suffered job loss. Figure A5 (discussed in the main text, and hence presented in Appendix A), shows sectoral trends in formal employment for men and women, with the red line marking the first outbreak of the pandemic. We observe particularly sharp declines in construction, hospitality, and artistic activities after March 2020. The construction sector employs a large share of the labour force, and mostly men. We supplement this information with data from a rolling labour market survey. Recognizing that the survey is not designed to be representative at the municipality level, we do not rely upon these estimates but provide them for descriptive purposes as they cover the entire population of formal and informal sector workers. Figure B8 shows increases in unemployment and declines in labour force participation rates for both men and women following the COVID-19 outbreak in March 2020. They reveal that, starting from a lower baseline level, unemployment rates of men increased more than rates for women. Starting from a lower base too, labour force participation rates of women fell more than rates for men.

\footnotetext{
${ }^{18}$ For this variable we extended the period beyond 30 September in order to use all the administrative information available. This allows us to pick up more lockdown exits in our data and to have more variation for a variable that is defined at the regional level.

${ }^{19}$ See Pappalardo et al. (2020) who also provide a description of the data.
} 
Finally, we obtained information on the total beneficiaries of the stimulus payments distributed since May 2020. This information comes from the Registro Social de Hogares. ${ }^{20}$ These payments were targeted at those families most severely affected by the socioeconomic crisis brought on by the pandemic. Figure A13 shows the scope of stimulus payments up to September 2020. During this time, four payments were distributed. Table A5 shows the timing and average amount of each one of these (again, as these figures are discussed in the main text, they are provided in Appendix A).

Figure B1: Descriptive trends—calls to \#149

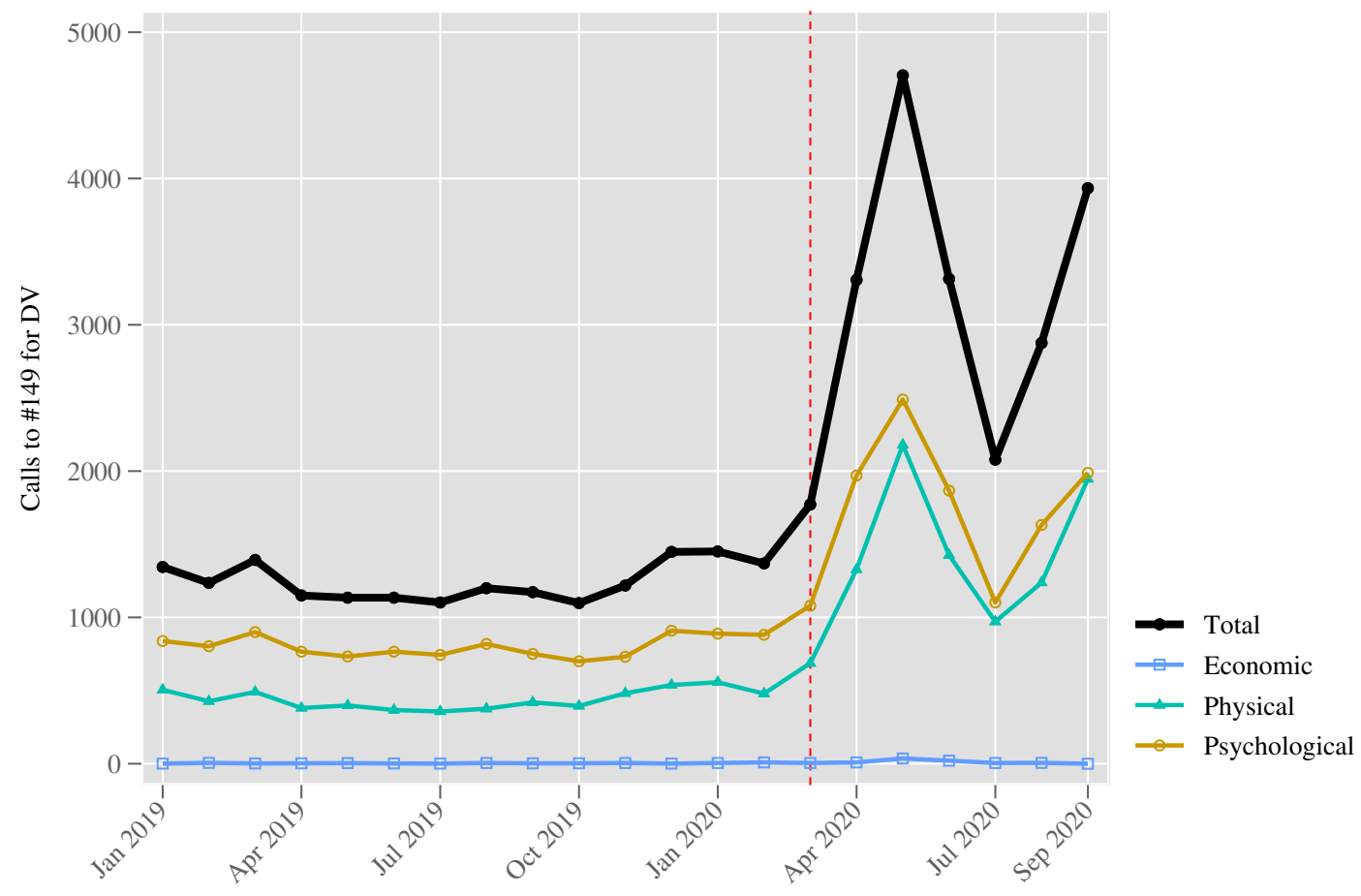

Note: total aggregate number of calls in the entire country are plotted for each month between January 2019 and September 2020. The thick black line refers to the total number of all calls related to domestic violence received by the Chilean Police. These are then sub-classified as related to psychological, phsyical, and economic violence. Vertical red line indicates March 2020 , the first month in which a lockdown was applied.

Source: authors' illustration based on data from Chilean Police (Carabineros de Chile).

20 This household register (RSH for its initials in Spanish) is an information system used by the Ministry of Social Development to assign a wide set of subsidies and social programmes. It combines verified self-reported information with administrative records. 
Figure B2: Descriptive trends—criminal complaints for intra-family violence

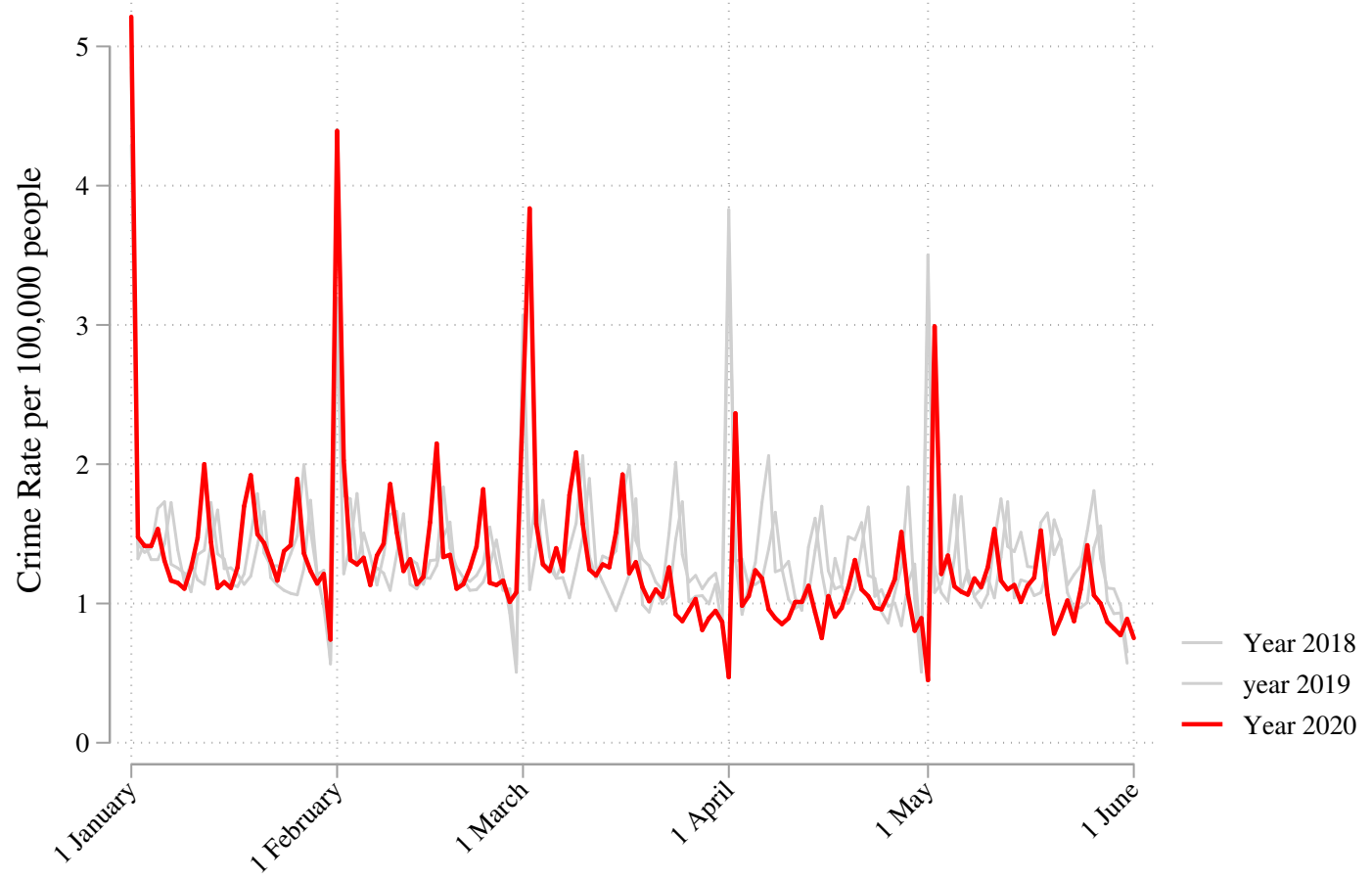

Note: rates of crime reporting for DV are plotted based on the number of reports received nationwide each day. Grey lines depict rates for the first five months of the years 2018 and 2019, while the red line depicts similar rates for 2020. In all analyses in the paper, month by municipality aggregates (over a longer period of time) are used.

Source: authors' illustration based on data from Ministry of Interior, Undersecretary of Crime Prevention.

Figure B3: Descriptive trends—residents in domestic violence shelters

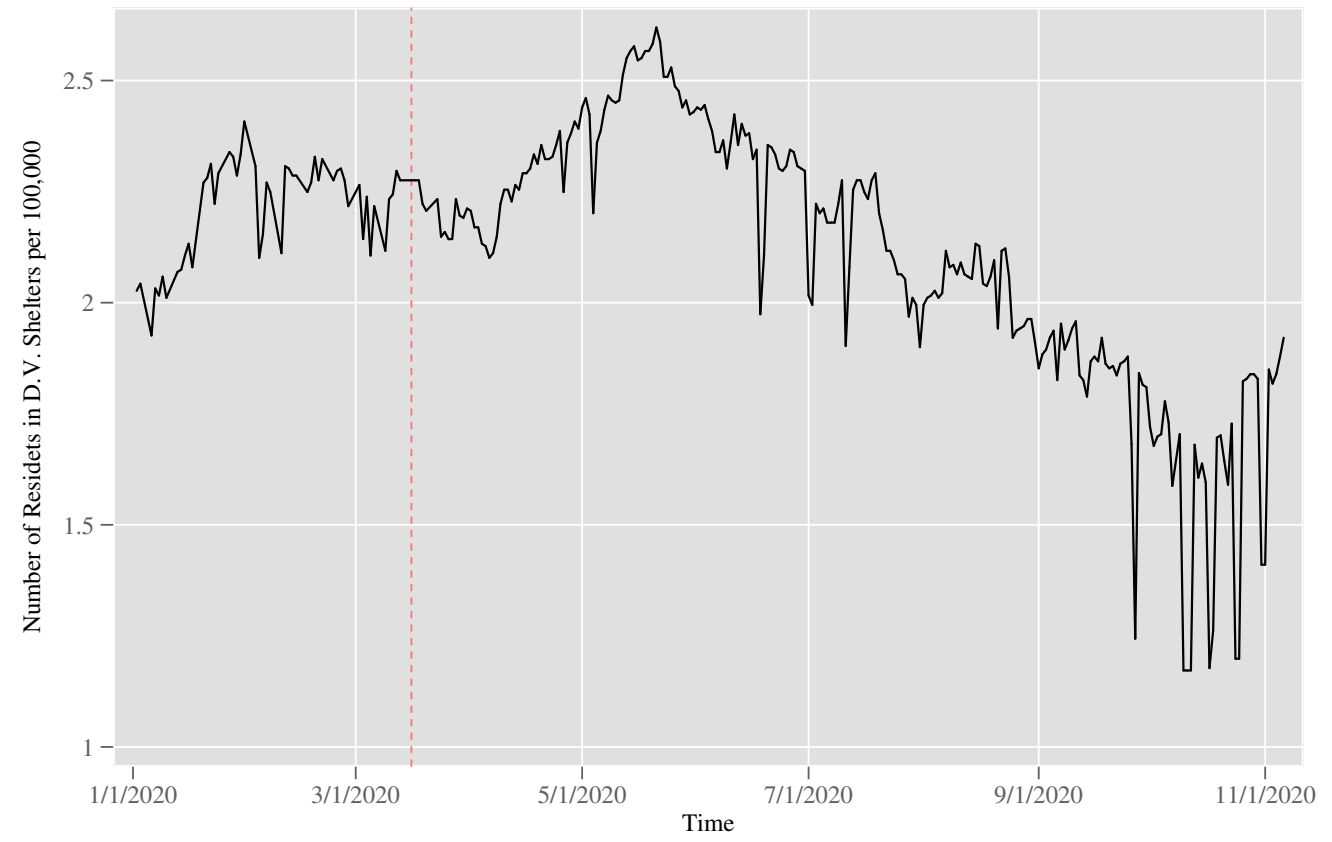

Note: the average rate of residence in government-run domestic violence shelters is plotted, calculated as the total proportion of residents who slept in a shelter the previous night. This figure covers state-run women's shelters. only.

Source: authors' illustration based on data from Ministry of Women and Gender Equality. 
Figure B4: National trends of official available spots in DV shelters (2020)

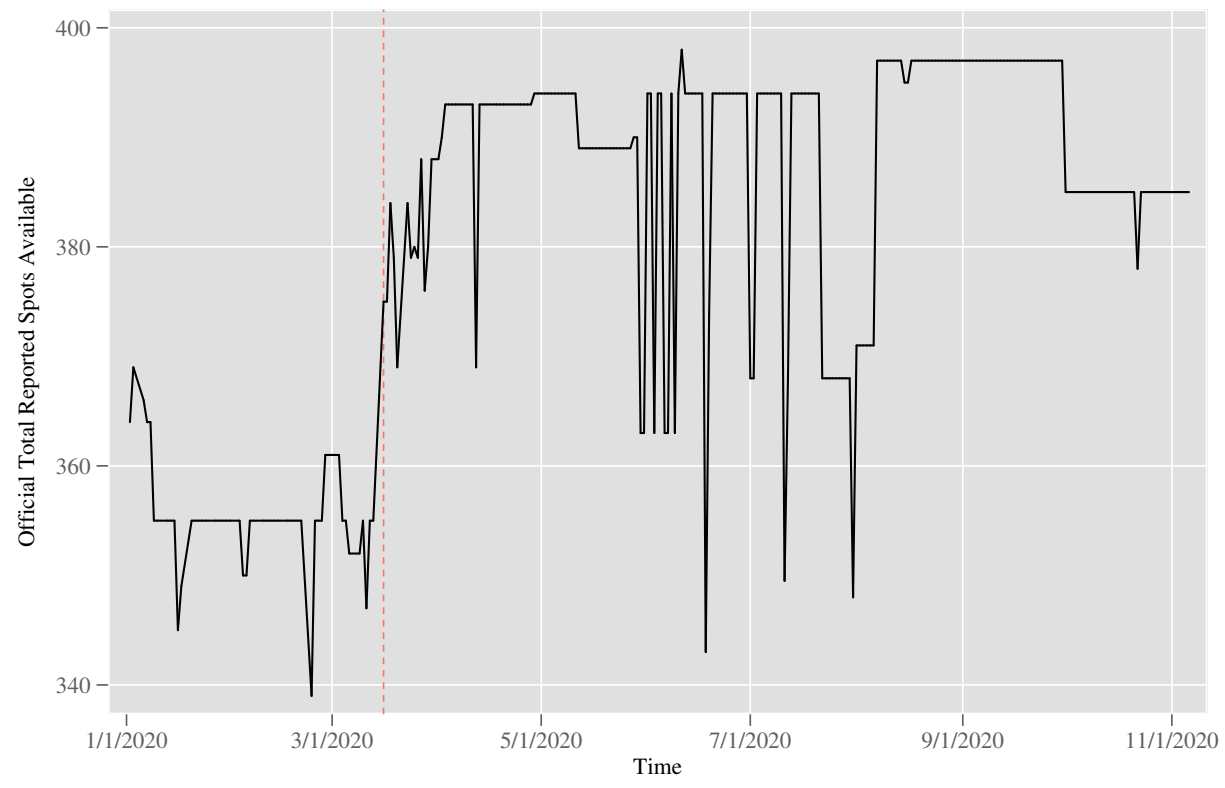

Note: temporal daily spikes on a small number of days owe to reporting gaps. This figure covers state-run women's shelters only.

Source: authors' illustration based on data from Ministry of Women and Gender Equality.

Figure B5: Raw correlations between measures of DV

$\begin{array}{ll}\text { (a) Crime reporting and shelter residence } & \text { (b) Shelter residence and distress calls }\end{array}$
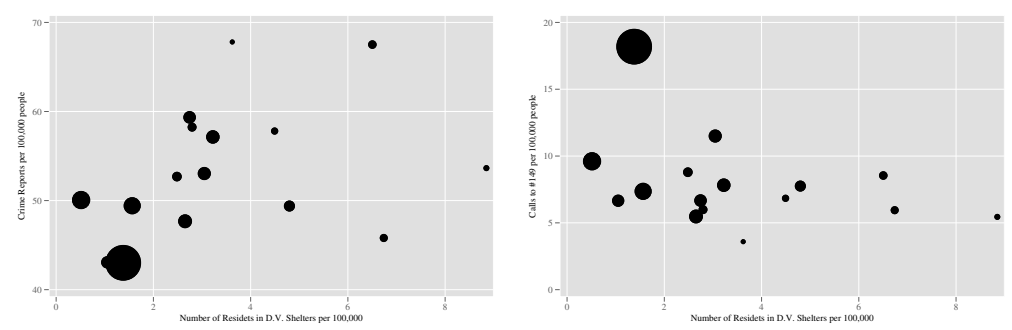

(c) Distress calls and crime reporting

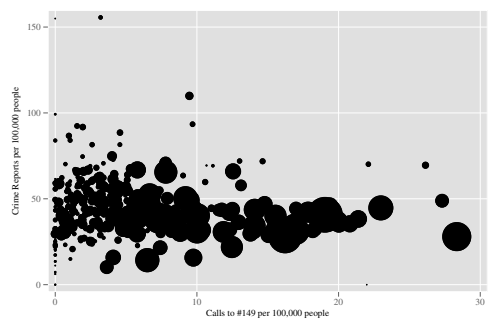

Note: plots document area-specific averages in rates of key DV measures between Jan-Sept 2020. In each case, averages are provided over the lowest level of aggregation possible (municipality in panel (c)), region in panels (a) and (b)). Point sizes are scaled by area populations.

Source: authors' illustration based on data from Chilean Police, Ministry of Interior, Undersecretary of Crime Prevention, and Ministry of Women and Gender Equality. 


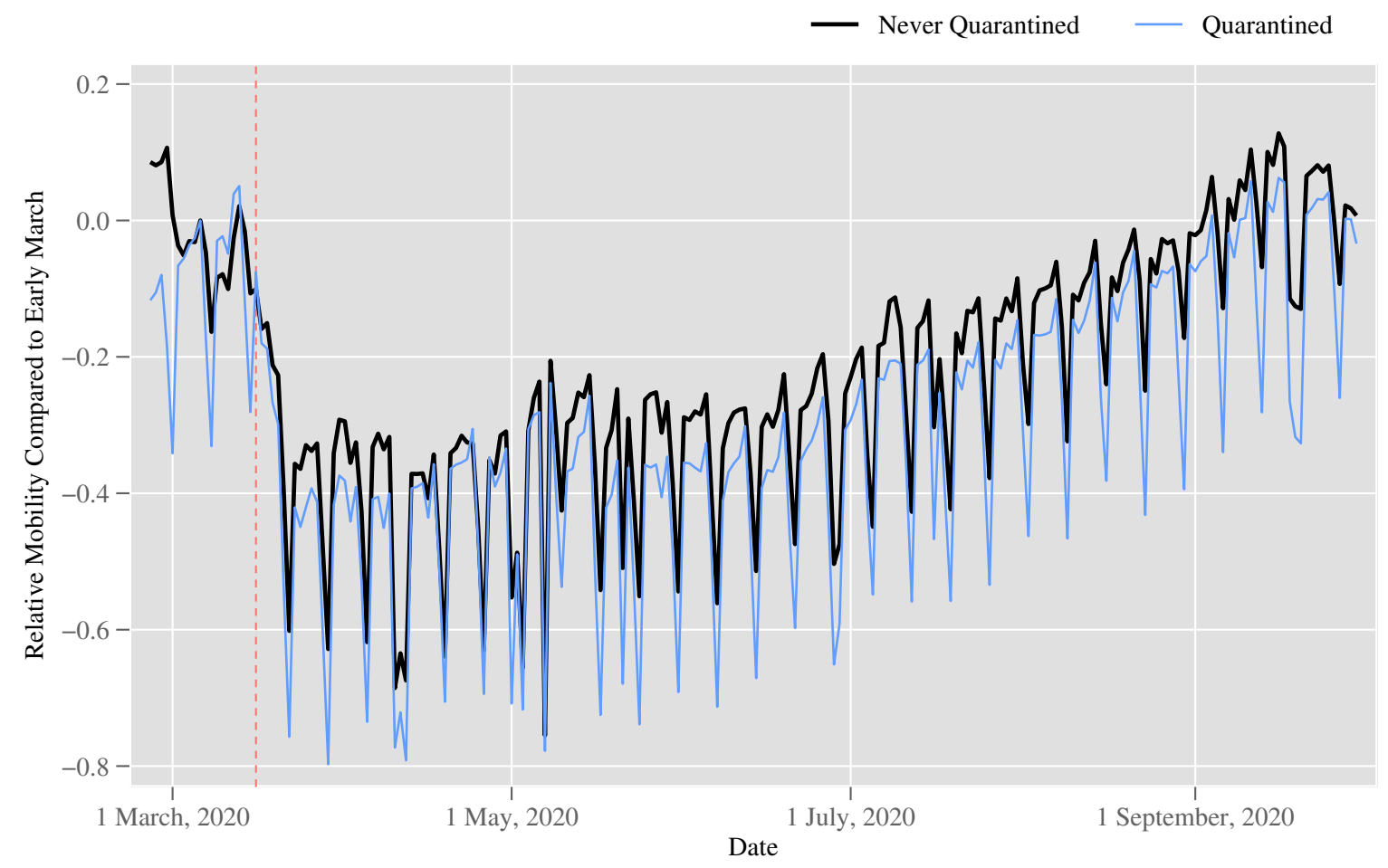

Note: the figure presents daily changes in mobility (relative to early March) for municipalities that were locked down and for those that were never locked down.

Source: authors' elaboration based on data described in Appendix B.

Figure B7: COVID-19 and changes in movement patterns
(a) Residential
(b) Workplaces

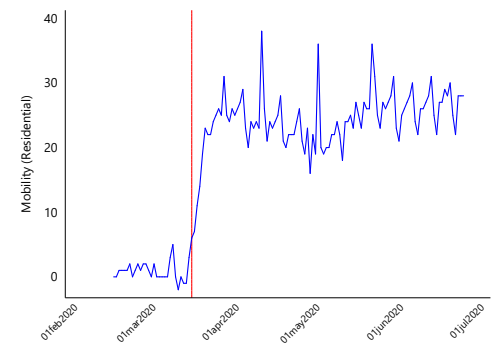

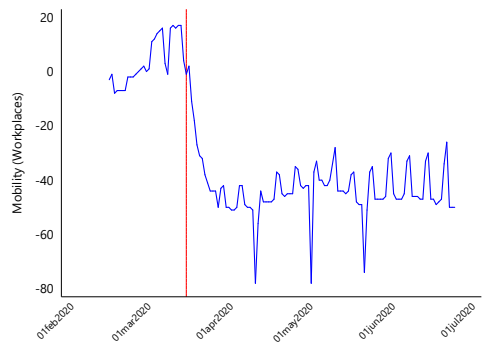

(c) Grocery

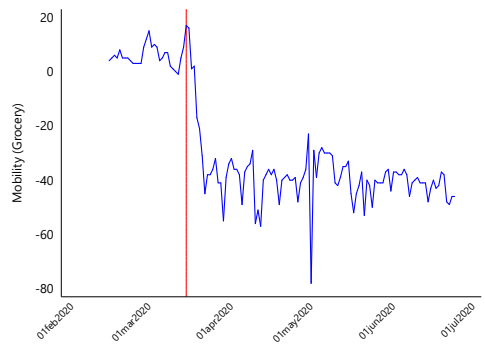

Note: the figure presents daily changes in mobility (relative to early March). Panel (a) shows mobility patterns in residential places, panel (b) shows workplaces, and panel (c) shows grocery stores.

Source: authors' elaboration based on data described in Appendix B. 
Figure B8: Economic indicators, 2019-20

(a) Unemployment rates

(b) Labour force participation rates
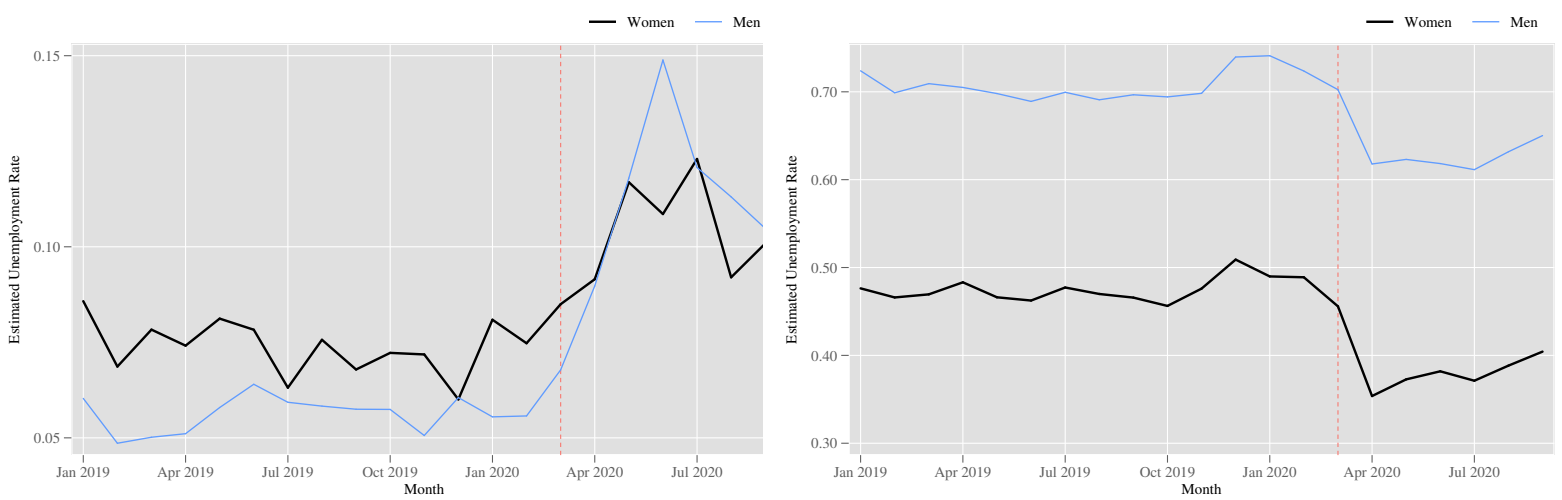

Note: the figure presents monthly changes in unemployment rates (panel (a)) and labour force participation rates (panel (b)) for men and women.

Source: authors' illustration based on data from the National Employment Survey (ENE). 
Table B2: Summary statistics of principal measures

\begin{tabular}{|c|c|c|c|c|c|}
\hline & Obs & Mean & Std. dev. & Min. & Max. \\
\hline \multicolumn{6}{|l|}{ Panel A: Distress calls } \\
\hline All calls to \#149 per 100,000 inhabitants & 7266 & 5.04 & 10.24 & 0.0 & 454.5 \\
\hline Calls to \#149 for economic violence per 100,000 & 7266 & 0.02 & 0.37 & 0.0 & 25.9 \\
\hline Calls to \#149 for physical violence per 100,000 & 7266 & 2.05 & 7.35 & 0.0 & 454.5 \\
\hline Calls to \#149 for psychological violence per 100,000 & 7266 & 2.96 & 5.37 & 0.0 & 112.5 \\
\hline \multicolumn{6}{|l|}{ Panel B: Criminal complaints } \\
\hline Total complaints to police for DV & 5190 & 21.68 & 34.60 & 0.0 & 364.0 \\
\hline Complaints to police for DV per 100,000 inhabitants & 5190 & 42.21 & 30.00 & 0.0 & 970.9 \\
\hline \multicolumn{6}{|l|}{ Panel C: Women's shelters } \\
\hline Residents in DV shelters per 100,000 inhabitants & 2336 & 3.67 & 2.39 & 0.0 & 11.3 \\
\hline Total capacity of DV shelters per 100,000 inhabitants & 2336 & 7.03 & 5.11 & 0.0 & 23.8 \\
\hline \multicolumn{6}{|l|}{ Panel D: Lockdown and mobility measures } \\
\hline Quarantine imposition & 75428 & 0.11 & 0.32 & 0.0 & 1.0 \\
\hline Quarantine exit & 75428 & 0.04 & 0.21 & 0.0 & 1.0 \\
\hline Mobility within the municipality per day & 74992 & 2.33 & 1.82 & 0.0 & 16.1 \\
\hline Mobility outside the municipality per day & 74992 & 3.43 & 3.05 & 0.0 & 41.1 \\
\hline Total mobility of the municipality per day & 74992 & 5.76 & 3.47 & 0.0 & 44.3 \\
\hline \multicolumn{6}{|l|}{ Panel E: Covid measures } \\
\hline COVID-19 testing rate & 71622 & 0.73 & 0.86 & 0.0 & 28.9 \\
\hline COVID-19 infection rate & 71622 & 0.09 & 0.21 & 0.0 & 12.5 \\
\hline COVID-19 positivity rate & 71622 & 11.3 & 16.8 & 0.0 & 100.0 \\
\hline \multicolumn{6}{|l|}{ Panel F: Economic measures } \\
\hline Unemployment rate (women) & 4984 & 0.08 & 0.12 & 0.0 & 1.0 \\
\hline Unemployment rate (men) & 4987 & 0.08 & 0.10 & 0.0 & 1.0 \\
\hline Estimated monthly employment rate (women) & 4984 & 0.44 & 0.15 & 0.0 & 1.0 \\
\hline Estimated monthly employment rate (men) & 4984 & 0.68 & 0.14 & 0.0 & 1.0 \\
\hline
\end{tabular}

Note: summary statistics cover measures used in the paper at the same level used in analysis (the most disaggregated level possible). For panels $\mathrm{A}, \mathrm{B}$, and $\mathrm{F}$, this is by municipality and month. For panel $\mathrm{C}$, this is by region (which includes multiple municipalities) and day. For panels $\mathrm{D}$ and $\mathrm{E}$, this is municipality by day.

Source: authors' elaboration based on data described in Appendix B. 